NBSIR $74-352(R)$

\title{
EXPERIMENTAL EVALUATION OF THE U.S. ARMY, WARRENTON TRAINING CENTER ANECHOIC CHAMBER
}

M.L. Crawford

Electromagnetics Division

Institute for Basic Standards

National Bureau of Standards

Boulder, Colorado 80302

November 1973

Prepared for

U.S. Army

Warrenton Training Center

Virginia 



\section{NBSIR 74-352}

\section{EXPERIMENTAL EVALUATION OF THE U.S. ARMY, WARRENTON TRAINING CENTER ANECHOIC CHAMBER}

M.L. Crawford

Electromagnetics Division

Institute for Basic Standards

National Bureau of Standards

Boulder, Colorado 80302

November 1973

Prepared for

U.S. Army

Warrenton Training Center

Virginia

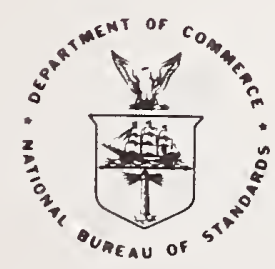

U.S. DEPARTMENT OF COMMERCE, Frederick B. Dent, Secretary 

CONTENTS

$\underline{\text { Page }}$

1. INTRODUCTION $\ldots \ldots \ldots \ldots$

2. SOME THEORETICAL ANALyS IS OF THE TAPERED CHAMBER--.- 5

3. DESCRIPTION OF MEASUREMENT SYSTEM AND TECHNIQUES - - - 10

4. EXPERIMENTAL RESULTS - . . . . . . . . . . . . . . . . 14

5. CONCLUSIONS AND RECOMMENDATIONS ............... 17

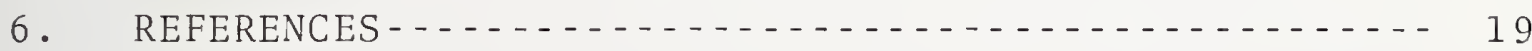

\section{LIST OF FIGURES}

Figure

$\underline{\text { Page }}$

1 Cross-Sectional View of Tapered Chamber......... 20

2 Simplified Plan Geometry of the Tapered Section of the Chamber Showing Quantities used in Calculation.

3 Three Dimensional Sketch of Chamber Geometry Showing Image of Reflection from Upper Wall to Field Point

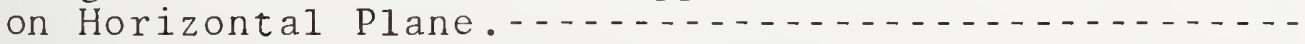

4 Calculated Amplitude Taper Across the Quiet Zone in both $\mathrm{E}$ and $\mathrm{H}-\mathrm{Pl}$ anes of the Transmit Antenna as a Function of Distance from the Center...........

5 Simplified Sketch Illustrating Total Aperture Field Variation Caused by a Single Specularly Reflected

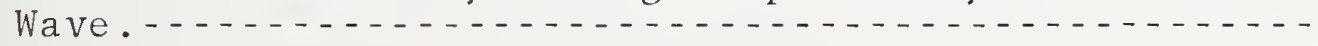

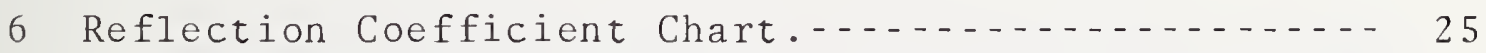

7 Block Diagram of NBS "Free Space VSWR" Measurement System. -...............................

8 Probe Mounted on Probe Traversing Mechanism Inside

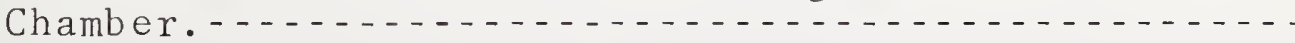

9 Instrument Circuit Functional Diagram.......... 28

10 Probe Response Pattern. 
LIST OF FIGURES (Continued)

Figure

$\underline{\text { Page }}$

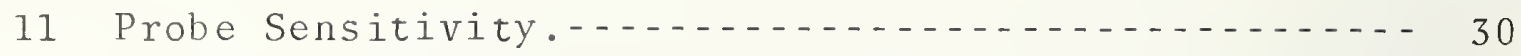

12 Photograph of Chamber Evaluation Probe and Meter.-. 31

13 Field Probe Traversing Mechanism Detail.......... 32

14 Recording of Field Amplitude Across Quiet Zone Vs. Probe Position for $X_{V}$ (Transverse), $Y_{V}$ (Vertical), and $Z_{V}$ (Longitudinal) Scans at $160 \mathrm{MHz}$. (Vertical

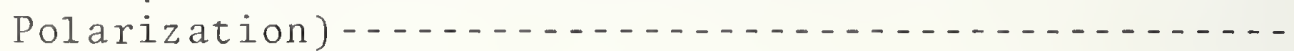

15 Recording of Field Amplitude Across Quiet Zone Vs. Probe Position for $X_{H}$ (Transverse), $Y_{H}$ (Vertical), and $\mathrm{Z}_{\mathrm{H}}$ (Longitudinal) Scans at $160 \mathrm{MHz}$. (Horizontal

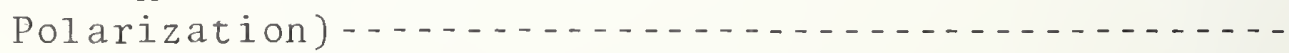

16 Recording of Field Amplitude for Extended Scans Centered on Quiet Zone Vs. Probe Position at $160 \mathrm{MHz} .35$

17 Recording of Field Amplitude Across Quiet Zone Vs. Probe Position With Model Tower in Place at $160 \mathrm{MHz}$. (Horizontal Polarization) -............... 36

18 Recording of Field Amplitude Across Quiet Zone Vs.

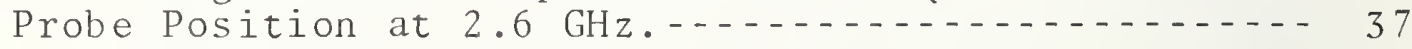

19 Recording of Field Amplitude for Extended Scans Centered on Quiet Zone Vs. Probe Position at $2.6 \mathrm{GHz}$.

20 Recording of Field Amplitude Across Quiet Zone Vs. Probe Position With Model Tower in Place at 2.6 GHz. 39

21 Recording of Field Amplitude for Extended Scan Centered on Quiet Zone Vs. Probe Position With Model

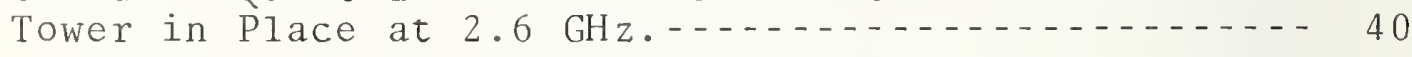

22 Recording of Field Amplitude Across Quiet Zone Vs. Probe Position at 4.0 $\mathrm{GHz} \ldots \ldots . \ldots 1$

23 Recording of Field Amplitude for Extended Scans Centered on Quiet Zone Vs. Probe Position at $4.0 \mathrm{GHz}$.

24 Recording of Field Amplitude Across Quiet Zone Vs. Probe Position at $8.0 \mathrm{GHz} . \ldots \ldots \ldots$ 
LIST OF FIGURES (Continued)

$\underline{\text { Figure }}$

$\underline{\text { Page }}$

25 Recording of Field Amplitude for Extended Scan Centered on Quiet Zone Vs. Probe Position at $8.0 \mathrm{GHz}$.

26 Summary of Chamber Quiet Zone Reflectivity and

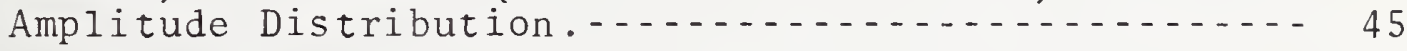

27 Chamber Polarization Measurements at $160 \mathrm{MHz}$.....- 46

28 Chamber Polarization Measurements at $2.6 \mathrm{GHz} . \ldots-\ldots 47$

29 Chamber Polarization Measurements at $4.0 \mathrm{GHz} . \ldots-\ldots 48$

30 Chamber Polarization Measurements at $8.0 \mathrm{GHz} . \ldots . . .49$

31 Summary of Chamber Symmetry/Polarization

Measurements......................... 50

32 Location of Source of Reflections Based Upon Period of Amplitude Ripple For X (transverse) Scans.-...- 51

33 Location of Source of Reflections Based Upon Period of Amplitude Ripple For Y (vertical) Scans....... 52

34 Location of Source of Reflections Based Upon Period of Amplitude Ripple For Z (longitudinal) Scans....- 



\section{EXPERIMENTAL EVALUATION OF THE \\ U.S. ARMY, WARRENTON, VIRGINIA, TRAINING CENTER, ANECHOIC CHAMBER}

This report describes the experimental performance evaluation of a 50-foot tapered anechoic chamber located at U.S. Army, Warrenton Training Center. Measurements of chamber reflectivity and polarization properties were made at four frequencies, $160 \mathrm{MHz}, 2.4 \mathrm{GHz}, 4.0 \mathrm{GHz}$, and $8.0 \mathrm{GHz}$. The measurement system developed by NBS for measuring chamber reflectivity utilizes a new NBSdesigned isotropic probe mounted on a polyfoam track and support structure for probing the chamber's quiet zone in all three orthogonal planes. The probe is omnidirectional within $1 \mathrm{~dB}$ and has sufficient sensitivity to permit evaluation of reflectivity levels as low as $-59 \mathrm{~dB}$. Complete scattering information is obtained without receive antenna pattern correction with only three orthogonal scans per frequency required. The report presents a brief treatment of the theory involved for evaluating the chamber, a description of the measurement system and technique used, the measurement results, and conclusions and recommendations including location of sources of reflection within the chamber.

Key words: Anechoic chamber evaluation; omnidirectional probe; polarization; reflectivity; three-dimensional scanning.

\section{INTRODUCTION}

This report describes the experimental performance evaluation of a tapered anechoic chamber 50 feet long located at U.S. Army, Warrenton Training Center. The measurements were made by the National Bureau of Standards, Boulder, Colorado (NBS), with support and assistance from Warrenton Training Center personnel. Funds were provided by Warrenton 
under contract WTC-538-74. Evaluation was performed to determine chamber reflectivity and polarization properties at four frequencies; $160 \mathrm{MHz}, 2.4 \mathrm{GHz}, 4.0 \mathrm{GHz}$, and $8.0 \mathrm{GHz}$.

Section 2 of the report presents a brief treatment of the theory involved in evaluating anechoic chambers. The system and measurement technique employed in evaluating the Warrenton chamber are described in section 3. Section 4 discusses the measurement results and presents the data in graphical form. Conclusions and recommendations are presented in section 5 .

There has always been a need to know what limitations exist in the use of anechoic chambers. Improvements in chamber design and absorber quality have extended their application and frequency range and placed new emphasis on accurate determination of the credibility of measurements made inside the chambers. The evaluation technique described in this report was developed at NBS in response to the need for an improved, accurate means of determining chamber performance.

Following the invention of the anechoic chamber, pattern comparison techniques have been used to determine performance. This technique, which has been reported in numerous sources $[1,2,3]$ is cumbersome and limited in completeness and accuracy. Because of different averaging techniques and different antennas used in this technique, chamber reflectivity measurement 
results varied considerably from chamber to chamber. A second evaluation technique, known as the "Free-Space VSWR" technique [4], utilizes field probing to determine signal strength within the chamber quiet zone as a function of probe position. By coupling the linear motion of the receiving antenna and the response of the receiver to a XY recorder, an interference pattern similar to a standing wave curve is obtained. The amplitude and period of these oscillations are then used to determine the amplitude and arrival angle of the interfering signal. Since the reflected or interfering signal in a chamber is the vector sum of many components arriving from different parts of the chamber, the results of each scan through the quiet zone are a function of the orientation and pattern of the receiving antenna. Typically, a number of scans are made with different aspect angles to obtain complete interference pattern information. Corrections are then made to the received data to account for the receive antenna pattern. This "VSWR" technique is usually considered more accurate for practical reasons than the pattern comparison technique [5], but it is still limited by the discrimination of the receive antenna to incoming signals arriving at angles within the pattern nulls. Experiments using the "VSWR" technique indicate that the use of receiving antennas with medium to high gain for reflectivity evaluation gives results that always favor the chamber performance [6]. 
The technique briefly described in this report utilizes a new NBS-designed receiving probe* consisting of three orthogonal dipoles designed to have essentially an isotropic receiving pattern. This type of probe responds equally (within $\pm 1 \mathrm{~dB}$ ) to signals arriving from any direction and with any polarization. Thus complete scattering information is obtained without receive antenna pattern corrections with only three orthogonal scans per frequency required. Sensitivity of the probe is sufficient to measure "free-space VSWR's" as low as $0.02 \mathrm{~dB}$ (chamber reflectivity $=59 \mathrm{~dB}$ ), using typical, moderate gain $(\simeq 10 \mathrm{~dB})$ source antennas driven by 10 -watt power oscillators. The probe's main limitation is its restricted use for pin-pointing sources of reflections within the chamber. This handicap is partially overcome by the probe's added feature of switchable dipole selection. This allows the use of the probe as a single dipole or combination of dipoles appropriate to the particular measurement need. If additional resolution for the location of the source of reflection is required, one can always replace the probe by higher gain receiving antennas oriented toward the suspect area.

*This probe was designed and built by R.R. Bowman and W.E. Jessen of NBS and was modeled after the NBS electromagnetic hazard probes but with greater sensitivity [7]. 
2. SOME THEORETICAL ASPECTS OF THE TAPERED CHAMBER

2.1 The Tapered Chamber as a Ground Reflection Range

A cross-sectional view of the Warrenton chamber is shown in figure 1. It is a truncated rectangular cone terminated in a right parallelepiped. At the lowest frequency of $160 \mathrm{MHz}$, the cone's absorber represents a fairly smooth reflecting surface and reflects a significant amount of energy into the chamber's quite zone. To examine this effect we consider first-order reflections as though they originated from image antennas located 90 degrees apart around the apex of the cone (see figure 2). By determining the path lengths of the reflected waves as the distances from the field point $P$ to the respective images, and with some simplifying assumptions, the field at point $P, E(P)$, can be expressed in terms of the direct-path field amplitude ${ }^{E_{D}}$.

$E(P)=E_{D}\left(e^{-j 2 \pi R_{D} / \lambda}+C_{1}\left(\frac{R_{D}}{R_{R_{1}}} e^{-j 2 \pi R_{R_{1}} / \lambda}+\frac{R_{D}}{R_{R_{2}}} e^{-j 2 \pi R_{R_{2}} / \lambda}\right)\right.$
$\left.+2 C_{2} \frac{R_{D}}{R_{0}} e^{-j 2 \pi R_{o} / \lambda}\right)$

${ }_{\mathrm{D}}, \mathrm{R}_{\mathrm{R}_{1}}, \mathrm{R}_{\mathrm{R}_{2}}$ are as shown in figure 2; $\mathrm{C}_{1}$ and $\mathrm{C}_{2}$ are the complex reflection coefficients from side walls and topbottom walls in the taper; $\lambda$ is the wavelength at the test frequency; and $R_{0}$ is the path length as shown in figure 3 
between the image of reflection from upper and lower walls to the field point on a horizontal plane. Details of the theoretical analysis are treated briefly in [2] and more completely in an evaluation report by T.G. Hickman and T.J. Lyon of Scientific Atlanta, Inc. [8].

The validity of eq. (1) is dependent upon a number of assumptions and approximations including a simplified fourimage reflection in the cone of the chamber, equal approximations of the reflection coefficients $C_{1}$ for the two side images, equal approximations of the reflection coefficients $\mathrm{C}_{2}$ for the top and bottom images, etc. Needless to say, calculations using eq. (1) yield only first-order approximations, but do give theoretical results typical of what is achieved in practice. Tapered chambers, by virtue of their design, typically have field amplitude uniformity across the quiet zone of a few tenths of a $d B$. The report referred to above [8], for example, contains the calculated amplitude distributions for the quiet zone of an 84-ft. tapered chamber. Figure 4 is a reproduction of these curves. Calculations for the Warrenton chamber were not made but should produce results similar to those shown in figure 4. Experimental measurements made of the amplitude distribution across quiet zone of the Warrenton chamber are contained in section 4 . 


\subsection{Chamber Reflectivity Level Evaluation}

Determination of the reflectivity level and angle of arrival of the interfering signal within the chamber's quiet zone is best understood by considering the simple case of a direct-path plane-wave signal of amplitude $\mathrm{E}_{\mathrm{d}}$ combining with an interfering plane-wave signal of amplitude $\mathrm{E}_{\mathrm{r}}$, arriving at the test point in the quiet zone at angle $\theta$ from the normal. Figure 5 gives a graphic illustration. A maximum occurs at points $x_{1}$ and $x_{2}$ produced by two reflected wave fronts whose phases differ by $2 \pi$ while assuming the phase of $E_{d}$ is constant. The resultant amplitude is

$$
\underline{E}_{\max }=\underline{E}_{\mathrm{d}}+\underline{E}_{\mathrm{r}} \cdot
$$

Halfway between these two points the waves are in phase opposition and the resultant amplitude is

$$
\underline{E}_{\min }=\underline{E}_{\mathrm{d}}-\underline{E}_{\mathrm{r}} \text {. }
$$

The maximum amplitude variation is thus given by

$$
\underline{E}=\underline{E}_{\max }-\underline{E}_{\min }=2 \underline{E}_{r} \cdot
$$

The angle $\theta$ can be determined by

$$
\theta=\sin ^{-1}(\lambda / d)
$$

where $d$ is as shown in figure 5 .

The field at any point in the quiet zone may also be represented as the sum of two phasors, $\underline{E}_{d}$ and $\underline{E}_{r}$ as illustrated in figure $5(\mathrm{c})$ where $\underline{E}_{\mathrm{r}}$ rotates relative to $\underline{E}_{\mathrm{d}}$. 
The phase of the field across the quiet zone will vary as the phase of the resultant of the direct-path and reflected phasors. The maximum phase variation for this case is

$$
2 \sin ^{-1} \underline{E}_{r} / E_{d}
$$

where $\underline{E}_{\mathrm{r}}$ is less than $\underline{E}_{\mathrm{d}}$. The stronger signal is assumed generally to be the direct signal. Figure 6 is a graph of the magnitude of the resultant field amplitude ripple (Free Space VSWR, $\left.\underline{\mathrm{E}}_{\max } / \underline{E}_{\min }\right)$ as a function of the ratio $\underline{\mathrm{E}}_{\mathrm{r}} / \underline{\mathrm{E}}_{\mathrm{d}}$.

The preceding example represents an idealized reflection. The actual ratio of $\underline{E}_{\mathrm{r}} / \underline{E}_{\mathrm{d}}$ within a chamber will vary from point to point due to the complex variation of the reflected signal(s). The reflected or interfering signal is the vector sum of many components arriving from different parts of the chamber. Also in a general test situation, neither the direct nor the extraneous waves will be strictly planar; however, the idealized representation does demonstrate the manner in which extraneous signals distort an otherwise planar wave front. For the case of tapered chambers, the region around the chamber axis is clear of reflecting objects with perhaps the exception of a model tower and head. In the evaluation, it may be necessary to remove the tower to evaluate the chamber's reflectivity. This is evident from reflectivity data obtained in the Warrenton chamber with and without the model tower in place. If the region around the chamber axis 
is clear of reflecting objects, the potential sources of extraneous energy are dissimilarities in the absorber on the walls, points of discontinuity at wall junctions and absorber transition regions, the positioner pit, and other objects placed in the chamber.

A typical recording in a chamber will show periodic amplitude variations (attributable to the chamber's imperfections) superimposed on the basic variations produced by changing path distance and beamwidths of the source and receive antenna patterns. Use of an isotropic receiving probe simplifies interpretation of the recorded results by eliminating the need for correcting for the antenna pattern and avoids discrimination against reflected signals arriving at angles aligned with nulls in the receive probe pattern. After the interference pattern is recorded, the periodic component is enveloped by drawing a line connecting the maximums and another connecting the minimums. The spacing between these two lines is the "Free Space VSWR" in dB. The worst case VSWR is indicated by the maximum vertical width between the two envelope curves.

\subsection{Chamber Polarization Properties Evaluation}

The use of anechoic chambers to determine antenna patterns requires a knowledge of the polarization properties of the chamber. In the absence of reflections and assuming 
chamber symmetry, rotation of the source (receiving) antenna about the chamber's axis for incremental rotations of the receiving (source) antenna should produce identical patterns. The degree and nature of the deviation in the measured polarization pattern is indicative of the polarization error introduced by the chamber. For these measurements, linear polarized antennas are typically used. In this case the received signal of interest is given by

$$
E_{r}=K \cos \left(\alpha-\tau_{T}\right)
$$

where $K$ is the received signal amplitude, $\alpha$ is the angle of rotation of the test antenna, and $\tau_{T}$ is the tilt angle of the degenerate polarization ellipse of the received wave. The receive antenna is mounted on the model tower head axis and patterns are taken by rotating the probe antenna through 360 degrees for systematically stepped rotational displacements of the source antenna about the line of sight. The measurements can be made for different placements of the transmit antenna along the axis of the chamber and for different receive antenna positions in the quiet zone.

3. DESCRIPTION OF MEASUREMENT SYSTEM AND TECHNIQUES

3.1 Determination of Distortion of the Incident Field in Quiet Zone

The technique used by NBS to evaluate the Warrenton chamber utilizes the "Free-Space VSWR" concept. Figure 7 gives a 
block diagram of the measurement system. Since the chamber performance is influenced by the source antenna characteristics and positioning, the chamber was evaluated using source antennas provided by Warrenton and used in their testing programs. These antennas were mounted in the throat of the chamber according to the procedure prescribed by the chamber manufacturer and adopted by Warrenton. The test probe developed by NBS was mounted on a polyfoam track attached to an NBS designed polyfoam tower. Figure 8 shows a picture of the probe traversing mechanism assembled inside the chamber. The test probe developed by NBS consists of three small, orthogonal dipole-diode antennas that separately sense the corresponding orthogonal components of the electric portion of the electromagnetic field. A functional diagram of the probe and metering circuit is given in figure 9. The three detected signals are transmitted away from the sensor by means of specially fabricated high-resistance lines that are essentially transparent to the electromagnetic field. Three preamplifiers buffer these signals, which are then summed in a scaling amplifier. This provides a composite signal that is proportional to $|E|^{2}=\left(|E|_{x}^{2}+|E|_{y}^{2}+|E|_{z}^{2}\right)$ at the position of the sensor. Switches are installed on each channel to allow display of the response of each channel separately or combined. The instrument is easily calibrated by placing the 
probe in either a "free-space" field or in a contained field (e.g., in a waveguide) of known intensity and polarization. The response of each channel and the composite are given in figure 10. The composite response is isotropic within $\pm 1 \mathrm{~dB}$. Probe sensitivity is given in figure 11. By using generators (with the source antennas) that are capable of producing test fields in the quiet zone of a few microwatts $/ \mathrm{cm}^{2}$, this sensitivity was adequate for reflectivity measurement resolutions of greater than $59 \mathrm{~dB}$. The limiting factor was the noise level generated by movement of the high-resistance transmission line connecting the probe dipoles to their sensor circuits. A high-resistance static shield around these lines accounted for the excellent noise factor allowing for the $59 \mathrm{~dB}$ plus resolution. A picture of the probe and meter is shown in figure 12 .

The probe traversing mechanism consists of a six-foot polyfoam track mounted on a polyfoam telescopic tower. A small carriage with the probe attached moves along the track via a system of pulleys, teflon guides, and counterweight. The movement is accomplished by pulling a polyester cord connected to the probe carriage and threaded through the pulleys, around the guides, and down to a plastic drum that is attached to a ten-turn potentiometer. The cord is wrapped around the drum, then through guides at the base of the tower and on outside the chamber. Figure 13 gives the traversing 
mechanism detail. The counterweight returns the probe to its starting position and resets the ten-turn potentiometer at the conclusion of each scan. The mechanism is designed for both vertical and horizontal operation. Thus, scans can be made through all three orthogonal axes of the chamber's quiet zone. Ideally, when designing such a probing device, material would be used that is transparent to the field to be measured. Practically, however, this is impossible. This traversing mechanism and probe represent a reasonable approximation to the ideal. The probe is small with essentially a transparent (to RF) transmission cable, and the scanning mechanism scatters or absorbs very little of the test field (dielectric constant of 1.045). Care must be used in assembling the tower and track. Experiments verified that some glues are not suitable for this type of application. They retain too much moisture.

\subsection{Test Procedure}

The probing mechanism is first assembled and oriented in the chamber with the probe pulled to one end. Next, the probe's metering circuit output is zeroed with the source (test field) turned off. A constant dc voltage is applied across the tenturn potentiometer to generate a voltage proportional to the probe location along the track. This proportional voltage is fed to the $X$-axis of an $X Y$ recorder and calibrated to indicate 
feet of probe movement. The amplitude output response from the probe-meter system is connected to the $\mathrm{Y}$-axis of the recorder and the source or test field is turned on. Calibration of the amplitude response ( $Y$-axis) in $d B$ is done by adjusting the source generator output using the power meter and directional coupler monitor. The probe is then moved along the track, and the interference signal is recorded on the $X Y$ recorder.

Determination of the polarization properties of the Warrenton chamber were very restricted because the model tower head was not operative. Rotation of the test antenna around the head axis had to be done manually at discrete steps, and the ability to align the antenna accurately at each step was limited. The procedure at the higher test frequencies ( 4.0 and $8.0 \mathrm{GHz}$ ) required very careful trimming of the source antenna axial alignment to locate the received cross polarization null. Variations in the depth of these nulls as a function of axial rotation were used to determine the polarization properties for the chamber. Results of these measurements are contained in section 4 .

\section{EXPERIMENTAL RESULTS}

The measurement results, using the techniques outlined in section 3, are presented primarily in graphic form. Figures 14 to 26 give the results of scans made to determine 
chamber reflectivity and amplitude distribution. The amplitude distribution of the received signal in an extended region including the quiet zone was determined by making overlapping scans. This was done by moving the NBS probe tower at 3 -foot intervals in the direction of the scan through the quiet zone. Since each scan was 6 feet 1 ong, three overlapping scans in each ( $X$ and $Z$ ) direction covered a 12-foot length. This procedure was followed to provide curve alignment and verification of measurement results as indicated in figure 16. Figures $16,19,21,23$, and 25 present this data. Each of the figures 14 to 25 gives pertinent data describing the source or transmit antennas used, its polarization, the calculated reflection level, $\rho$, and the angle of arrival, $\theta$, of the dominate reflected signal for each scan axis, X (transverse), Y (vertical), and Z (longitudinal). The scan orientation is given on each graph. A summary of the chamber reflectivity and quiet zone amplitude distribution, extracted from figures 14 to 25 is given in the table of figure 26 . Figures 27 to 30 give the results of chamber symmetry/polarization measurements. In each case the axial ratio was obtained by rotating the source antenna for various fixed orientations of the receive antenna. Data were obtained for the four frequencies, $160 \mathrm{MHz}, 2.6 \mathrm{GHz}, 4.0 \mathrm{GHz}$, and 8.0 $\mathrm{GHz}$, and are summarized in figure 31. 
Finally, a few comments are in order regarding interpretation of the measurement results. Measurements at $160 \mathrm{MHz}$ required a large scan area to obtain enough of the interference pattern in the quiet $z$ one to determine the reflected signal level. Variations in the amplitude distribution somewhat limit the ability to resolve interference resulting from reflections. Part of this problem was solved by taking data over a $12-\mathrm{ft}$. area rather than over the designated 6 -ft. quiet zone. Also, insight into the anticipated amplitude distribution due to spatial loss of the source signal ( $Z$ scan) or taper roll off (X scan) helped to resolve this. It should be noted that the measured amplitude distribution in the quiet zone is not as smooth as one would expect for this type of chamber. This, it is believed, is due to misalignment of the cone at the apex of the chamber. This misalignment was visually evident when mounting and aligning the source antenna with the chamber axis. It was also apparent, see figures 20 and 21 , that reflections from the model tower were important, especially as the test frequency is increased. This necessitated the removal of the model tower to obtain an accurate determination of the chamber's reflective properties. Since the chamber is normally used with the model tower and head in place, it is well to be aware of its potential influence on the measurement results. 
The scatter of the model tower head may not be serious if the antenna under test (mounted to the head) presents blockage to the head or has sufficient forward gain. However, if this is not the case, it would be well to use non-metallic material in the head construction.

Scatter or reflections from the probe transport tower become more pronounced at higher test frequencies. This was especially apparent when the source antenna was horizontally polarized. Evaluation of the reflectivity data at $8.0 \mathrm{GHz}$ disclosed that more reflections were resulting from the probe support structure than from the chamber. This limited the measured results at this frequency to approximately $-45 \mathrm{~dB}$. At lower frequencies, the scatter from the probing structure becomes less apparent while the chamber's reflections increase.

\section{CONCLUSIONS AND RECOMMENDATIONS}

One primary concern is the large signal amplitude (as much as $2.0 \mathrm{~dB}$ ) variation through the quiet zone. This is very similar to what one would expect from operation in a rectangular chamber or if the source antenna was removed far enough from the tapered chamber apex to allow spectral reflection to occur from the side walls, floor, and ceiling. The quiet zone amplitude distribution should be less than a few tenths $d B$ for uniform illumination in high-accuracy antenna tests. 
Calculations of chamber reflection arrival angle indicate the largest contribution regions are:

1. the junction of floor and taper transitions;

2. the junction of ceiling and taper transitions; and

3. the back wall, especially at $160 \mathrm{MHz}$.

Figures 32 to 34 give a graphical interpretation of these reflection areas for each scan axis.

Because of the limitations in determining the polarization properties of the chamber for this evaluation, it is recommended that these measurements be repeated by Warrenton after the model-tower-head's axial rotation drive is operative. This will allow complete axial rotation patterns to be compared for stepped axial rotation position of the source antenna and should give a more accurate chamber symmetry evaluation.

A grounding problem in the transmit room was discovered during the initial measurements. The ground connection between the source antenna and its generator is not isolated from the antenna support structure. Thus, if balanced antennas with baluns are used, RF is conducted along this structure and reradiates into the transmit room. Movement of personnel inside the room was detected by the receive probe mounted in the quiet zone of the chamber. This problem was avoided by clearing all personnel out of the transmit room during the measurements, but it is suggested that this problem be corrected. 


\section{REFERENCES}

[1] R.H. Hiatt, E.F. Knott, and T.B.A. Senior, "A Study of VHF Absorbers and Anechoic Rooms," Radiation Lab., Univ. Michigan, Tech. Rep. 5391-1-F., Feb. 1963.

[2] R.R. Bowman, "Prevalent Methods for Evaluating Anechoic Chambers: Some Basic Limitations," presented at 1966 Measurement Seminar, Session III, Lecture 3 of High Frequency and Microwave Field Strength Precision, NBS Report (unpublished).

[3] "Antenna Pattern Range Evaluation by Pattern Comparison Method," Emerson \& Cuming, Inc., Canton, Mass./Gardena, Calif., Aug. 1963.

[4] W.H. Emerson and F.W. Browne11, "Measurement of Various Chambers," Various contractor and agency reports from MR-07 through MR-80. Emerson \& Cuming Inc., Canton, Mass./ Gardena, Calif.

[5] J. Appe1-Hansen, "Reflectivity Leve1 of Radio Anechoic Chambers," IEEE Trans. on Ant. and Prop., Vol. AP-21, No. 4, Ju1y 1973.

[6] H. Hollman, "Design and Function of Anechoic Funnel and Rectangular Chambers for Antenna Tests," Fermeldetech, Z. der Deutschen Bundespost, A 454 TBr 13, Nov. 1971.

[7] R.R. Bowman, E.B. Larsen, D.R. Belsher, and P.W. Wacker, "Second Progress Report: Electromagnetic Hazards Project," NBS Report (unpublished), Sept.18. 1970

[8] T.G. Hickman and T.J. Lyon, "Experimental Evaluation of the Massachusetts Institute of Technology, Lincoln Laboratory Anechoic Chamber," Scientific-Atlanta, Inc., Atlanta, Georgia, Report submitted under Contract AF 19(628) 5167, June 1968. 

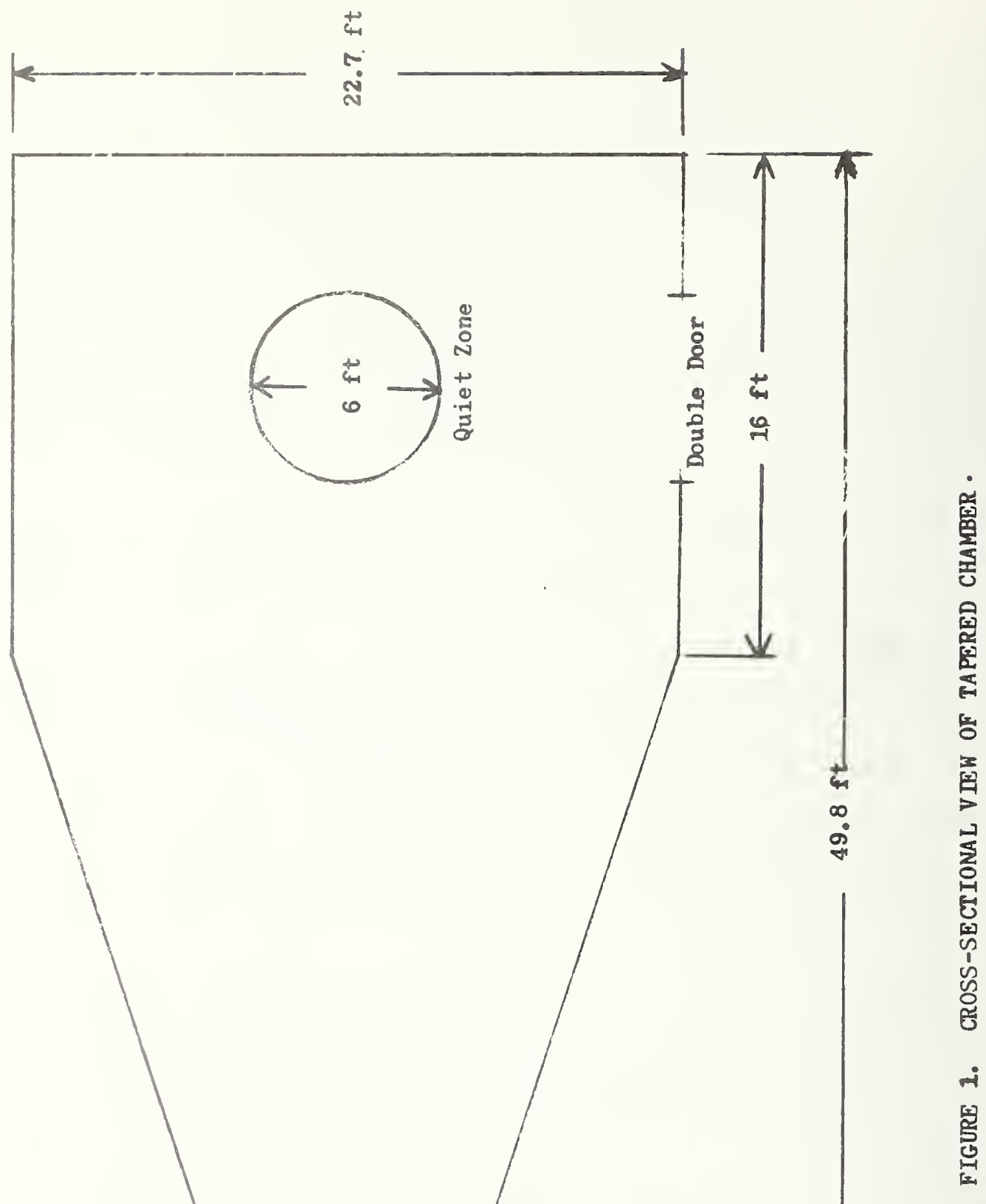

20. 


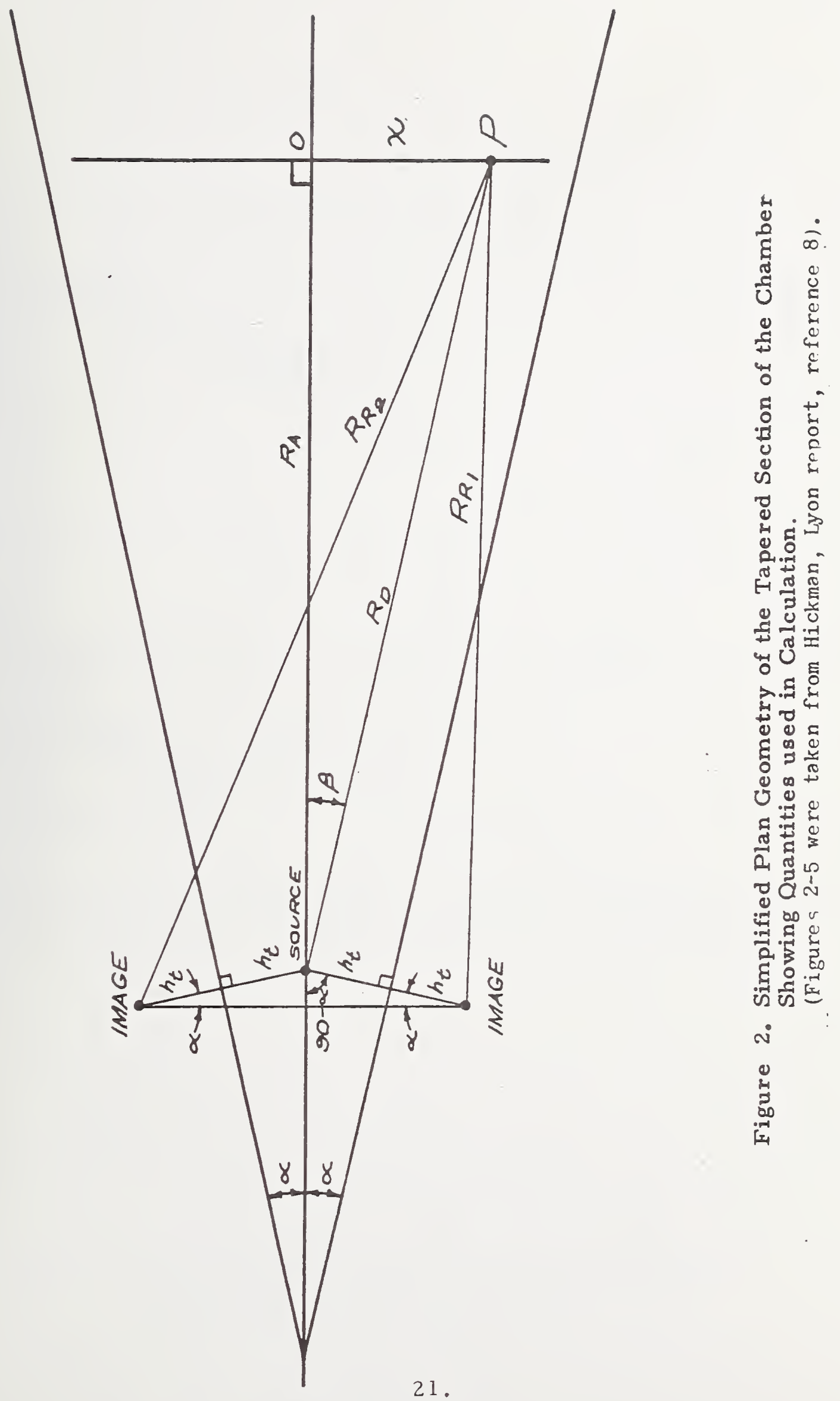




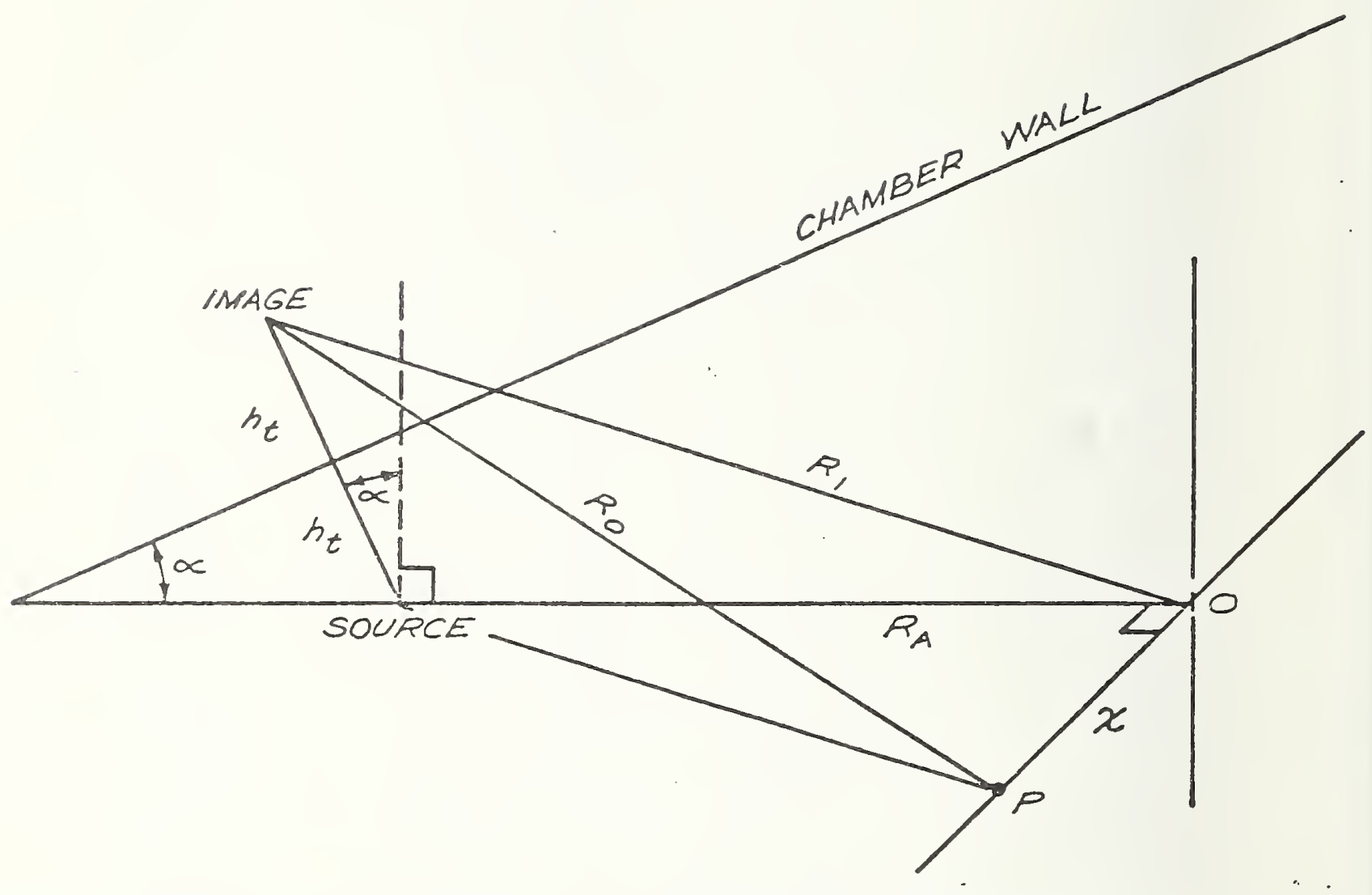

Figure 3. Three Dimensional Sketch of Chamber Geometry Showing Image of Reflection from Upper Wall to Field Point on Horizontal Plane. 

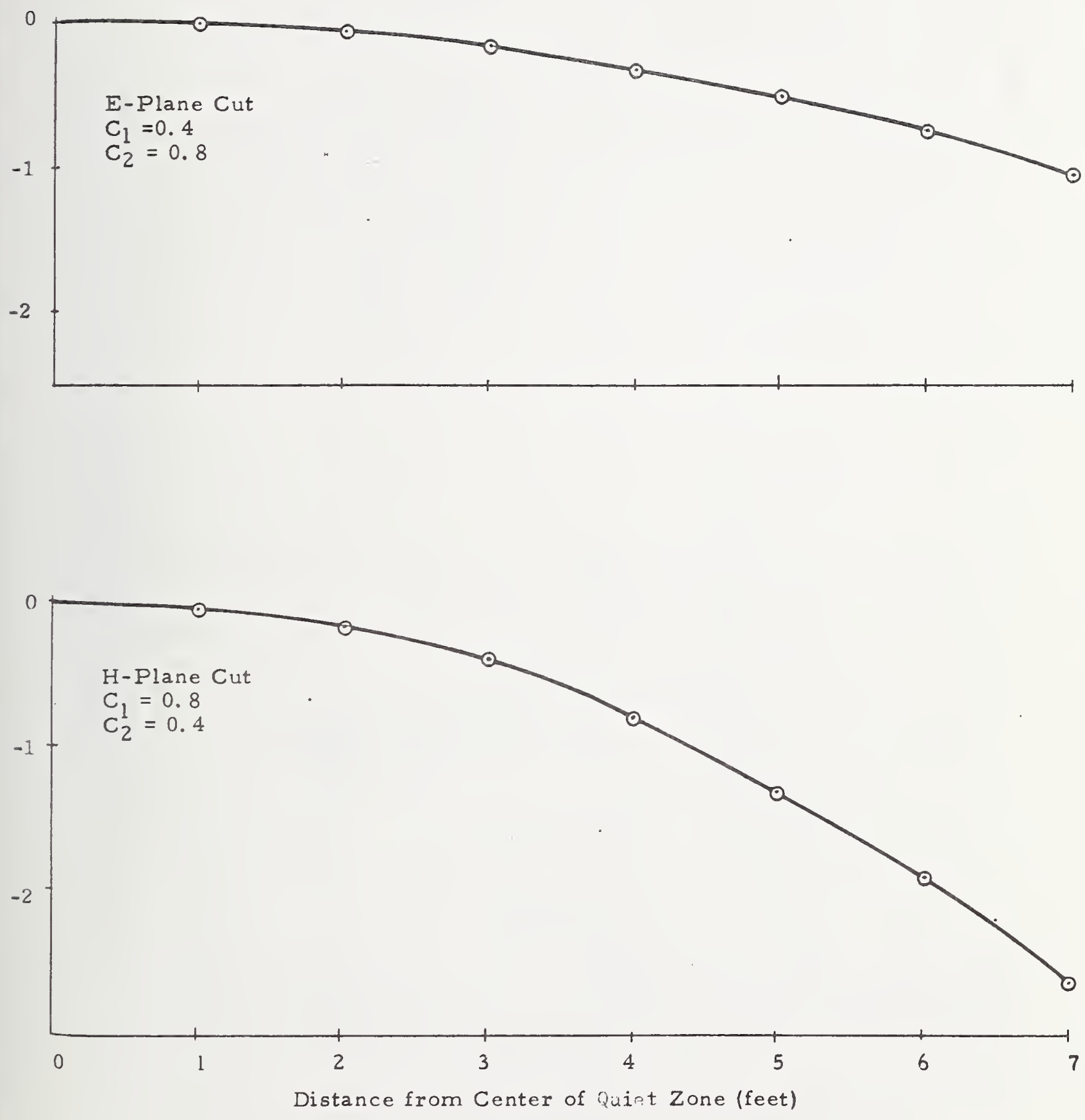

Figure 4. Calculated Amplitude Taper Across the Quiet Zone in both $E$ and $H-P l a n e s$ of the Transmit Antenna as a Function of Distance from the Center. 

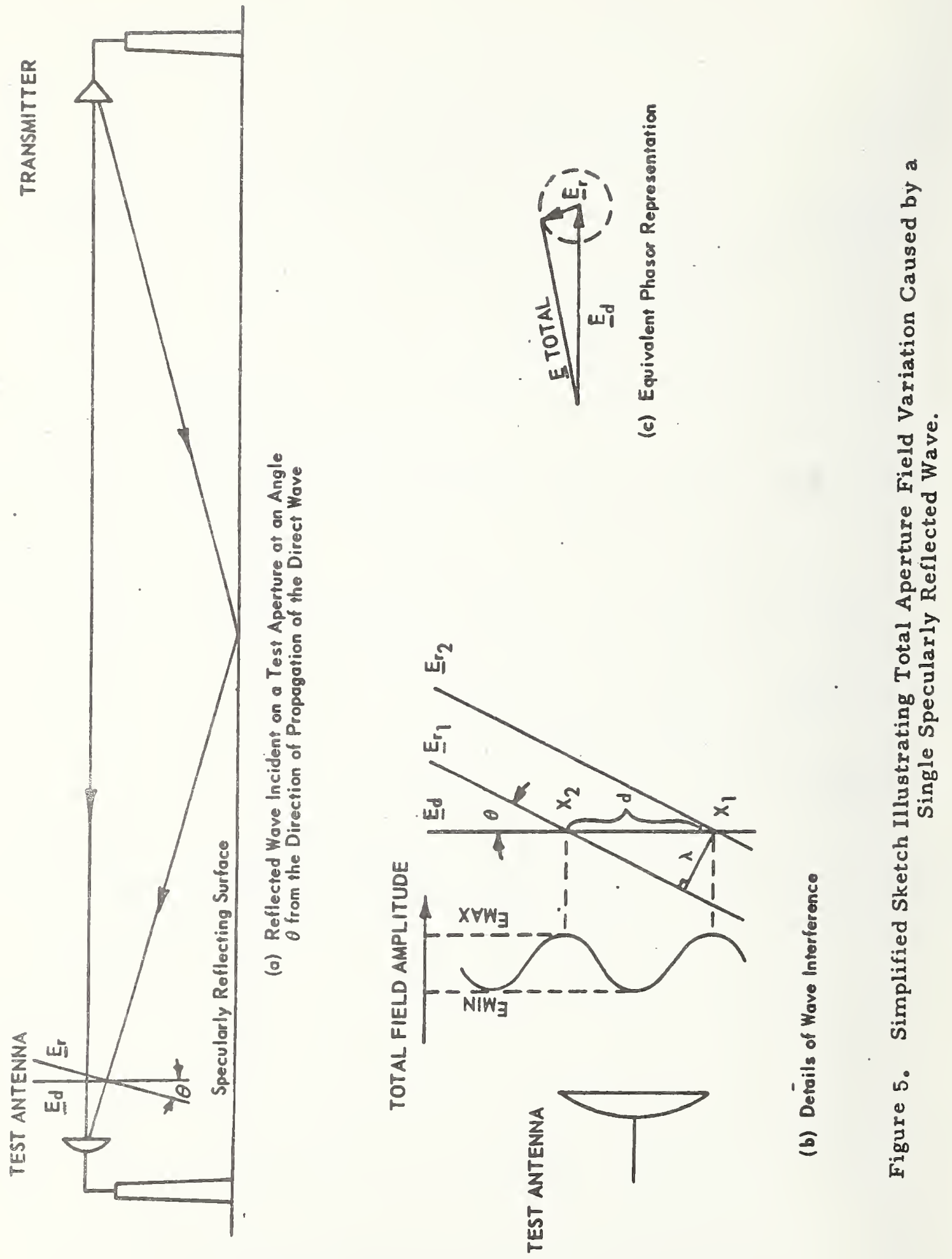


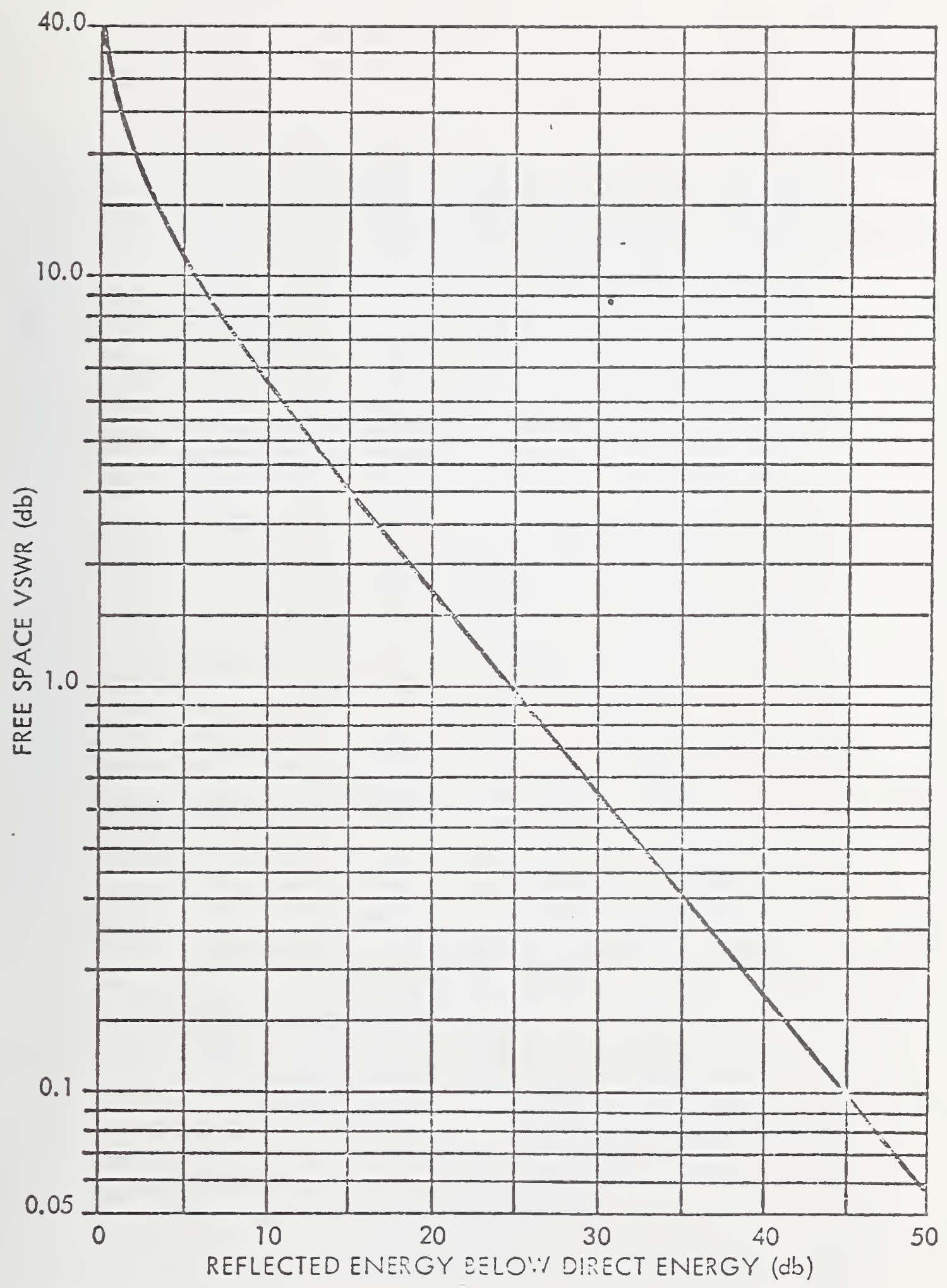

Figure 6. Reflection Coefficicnt Chart. 


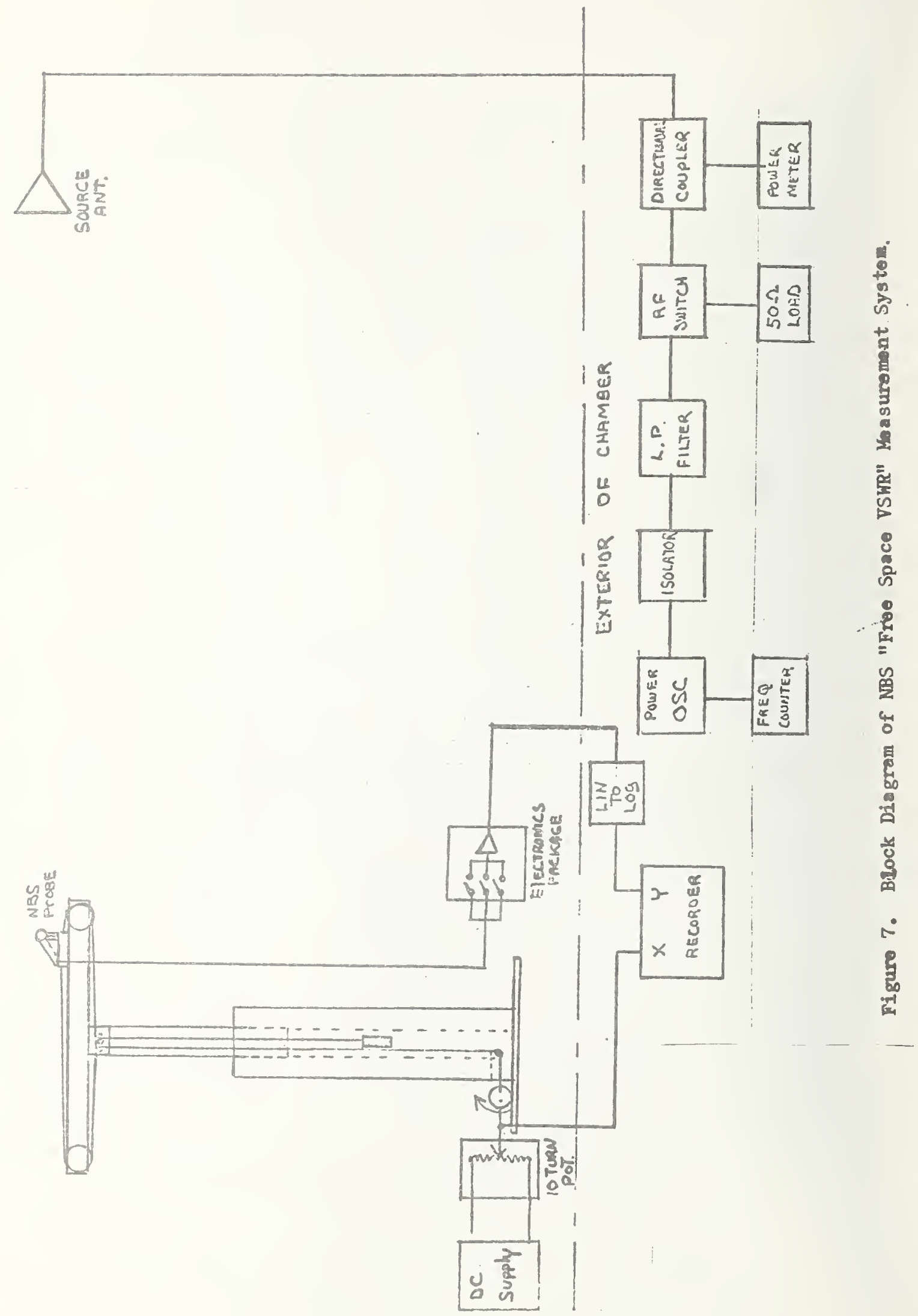




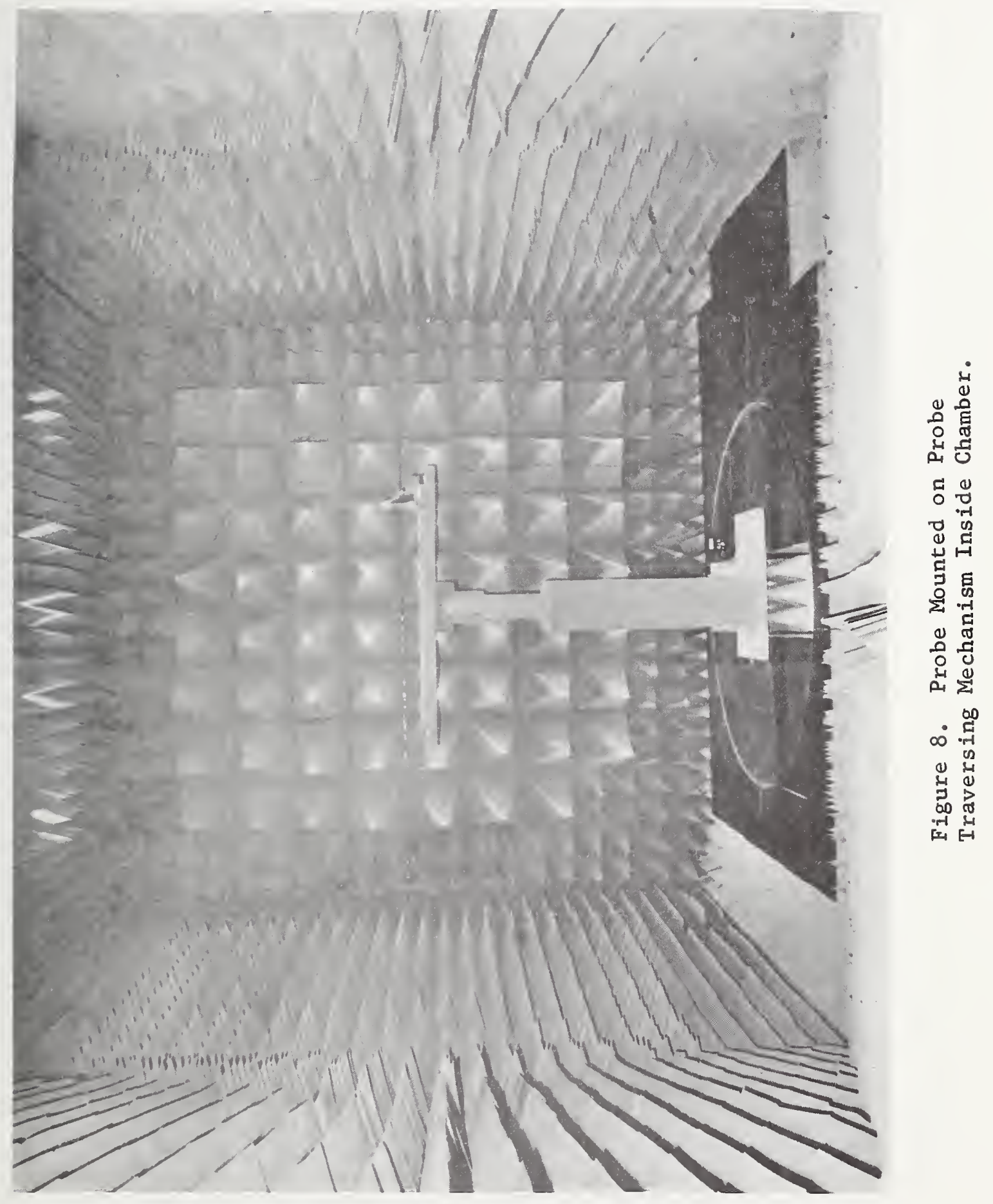




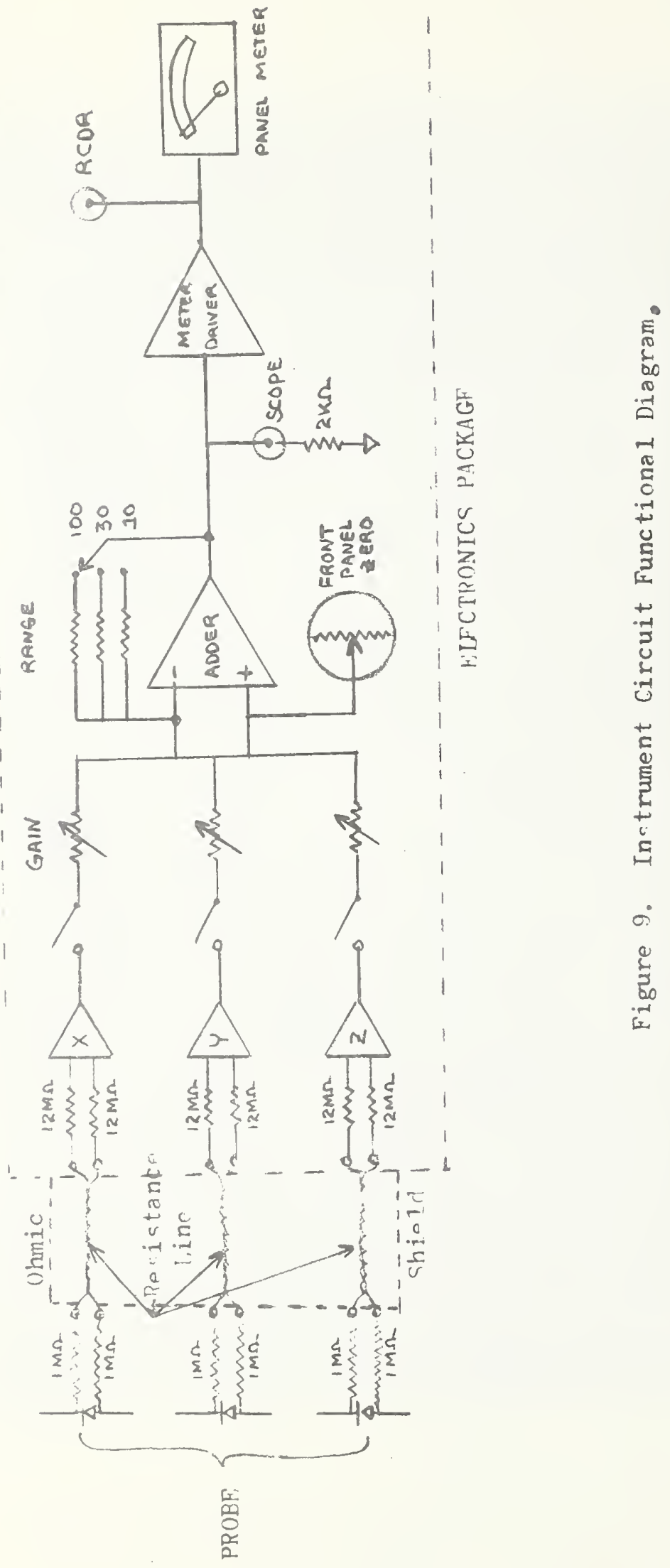




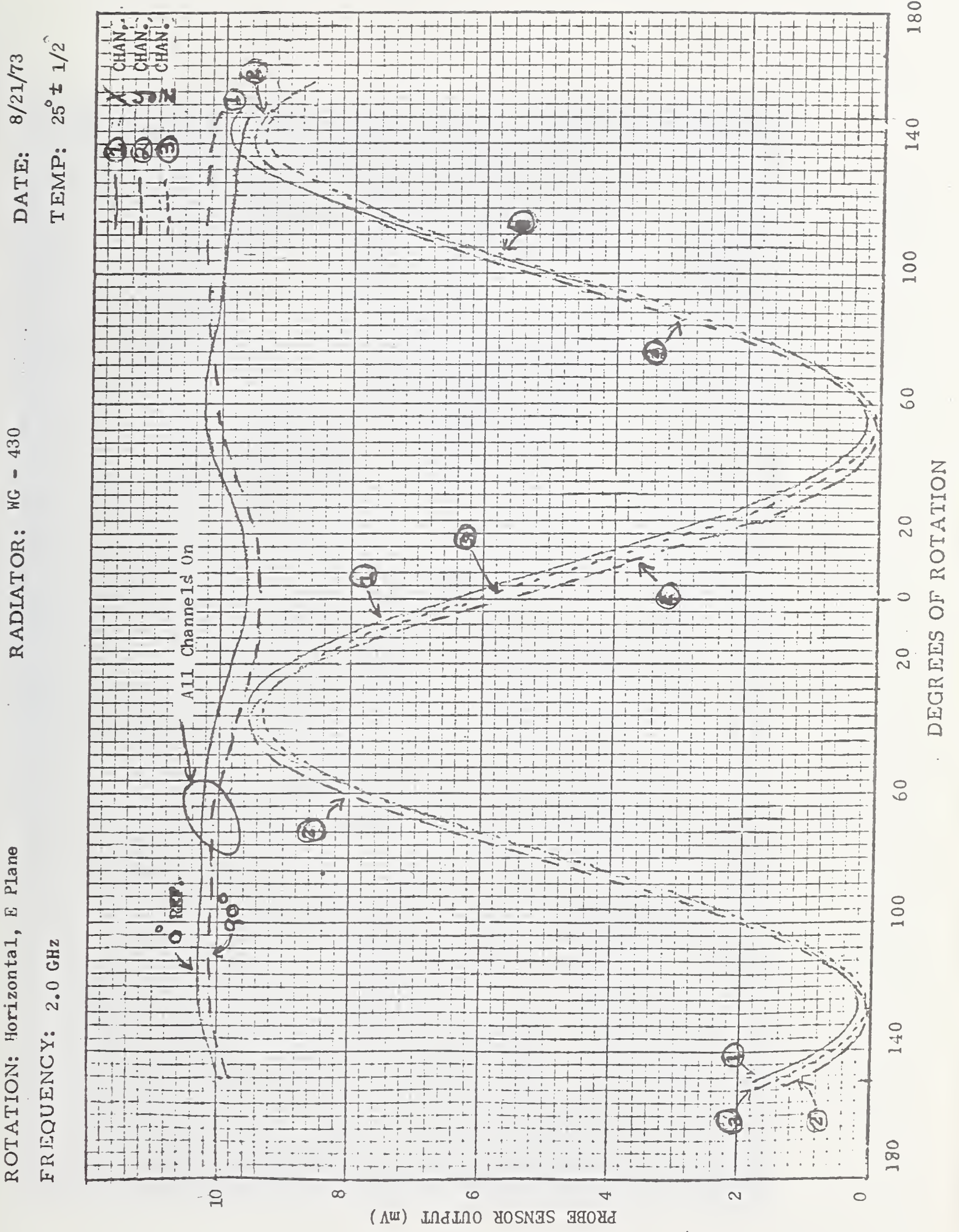




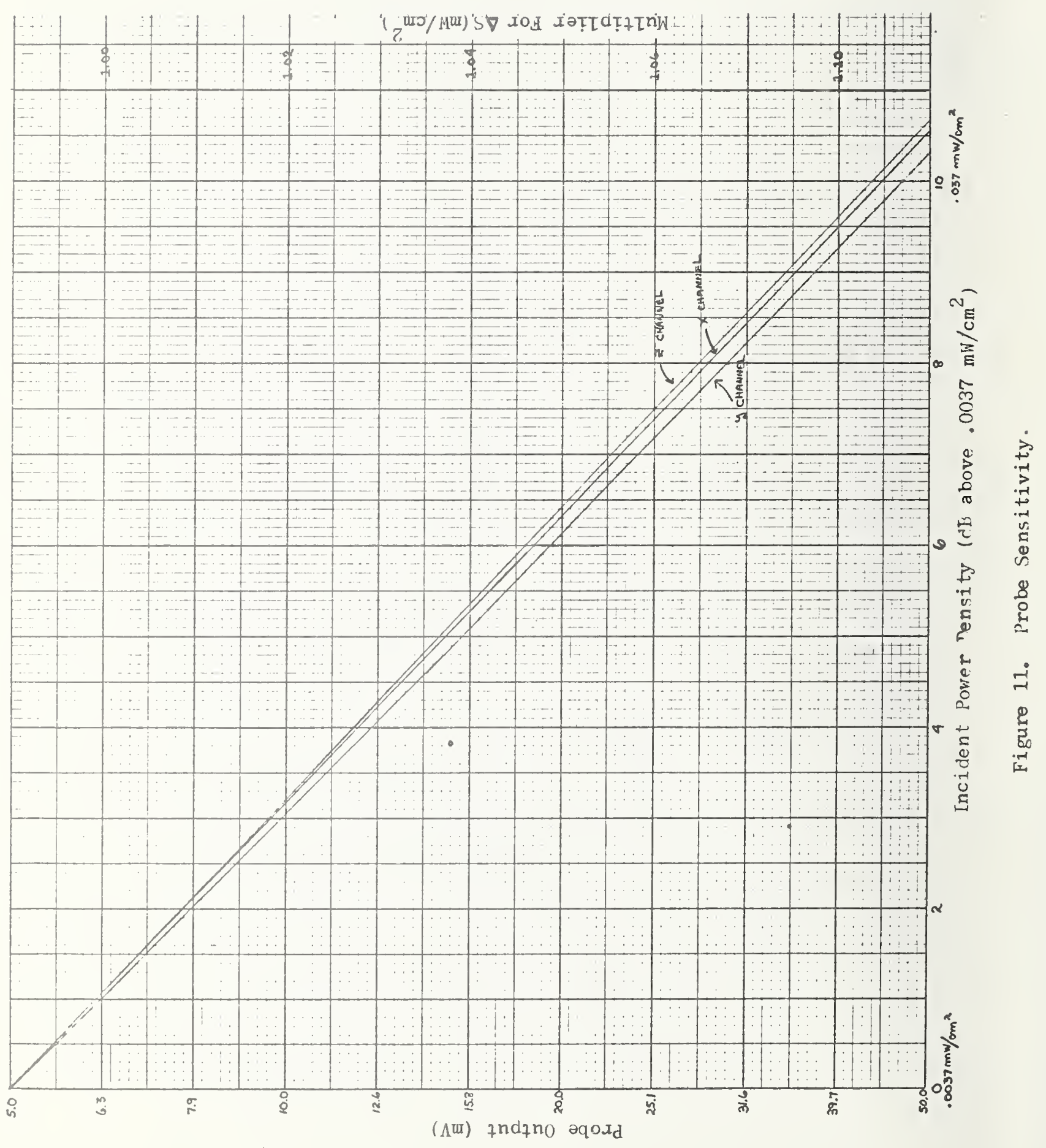




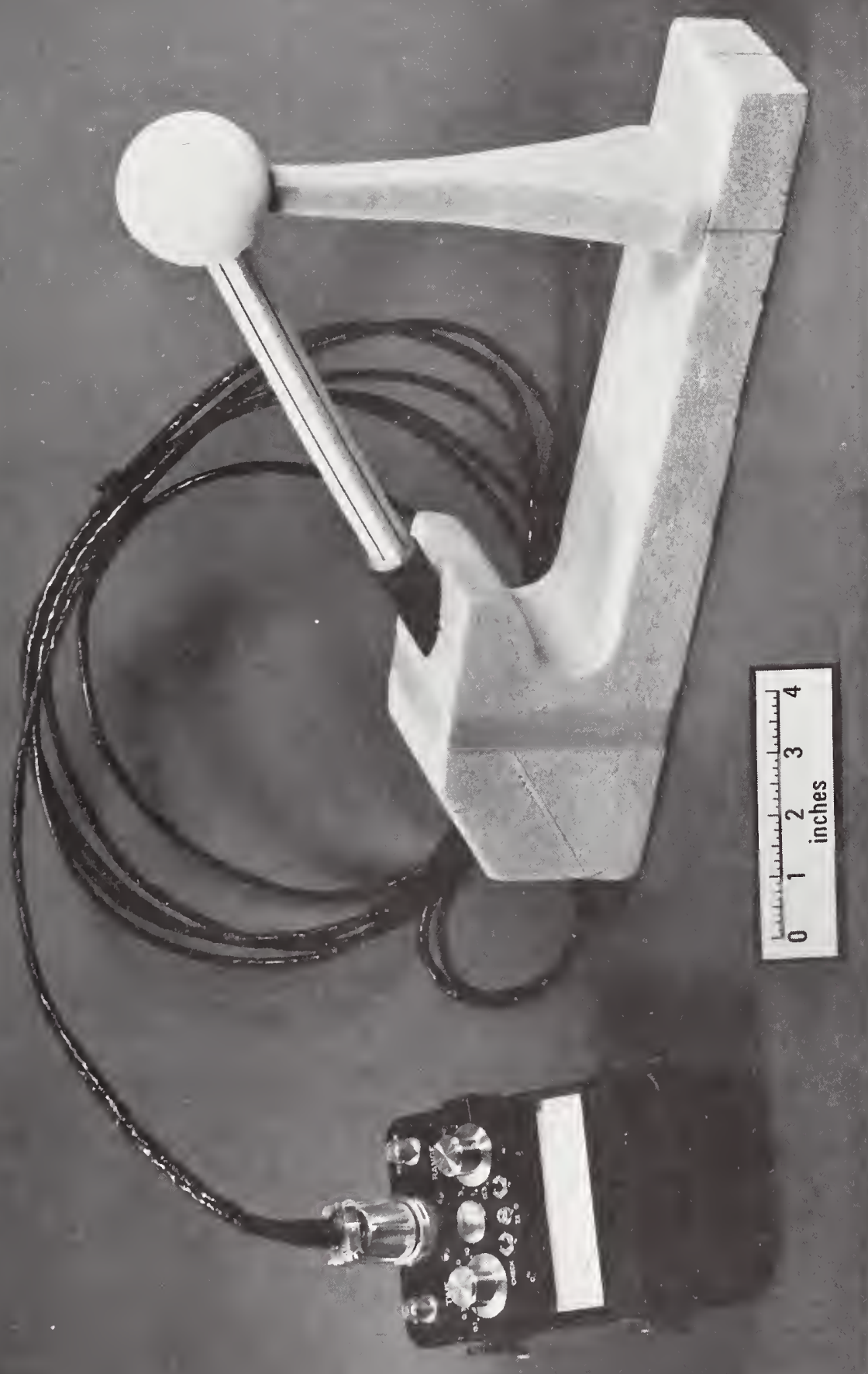

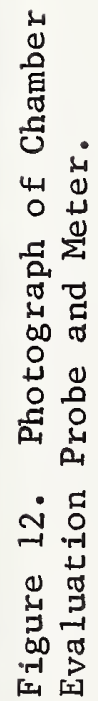




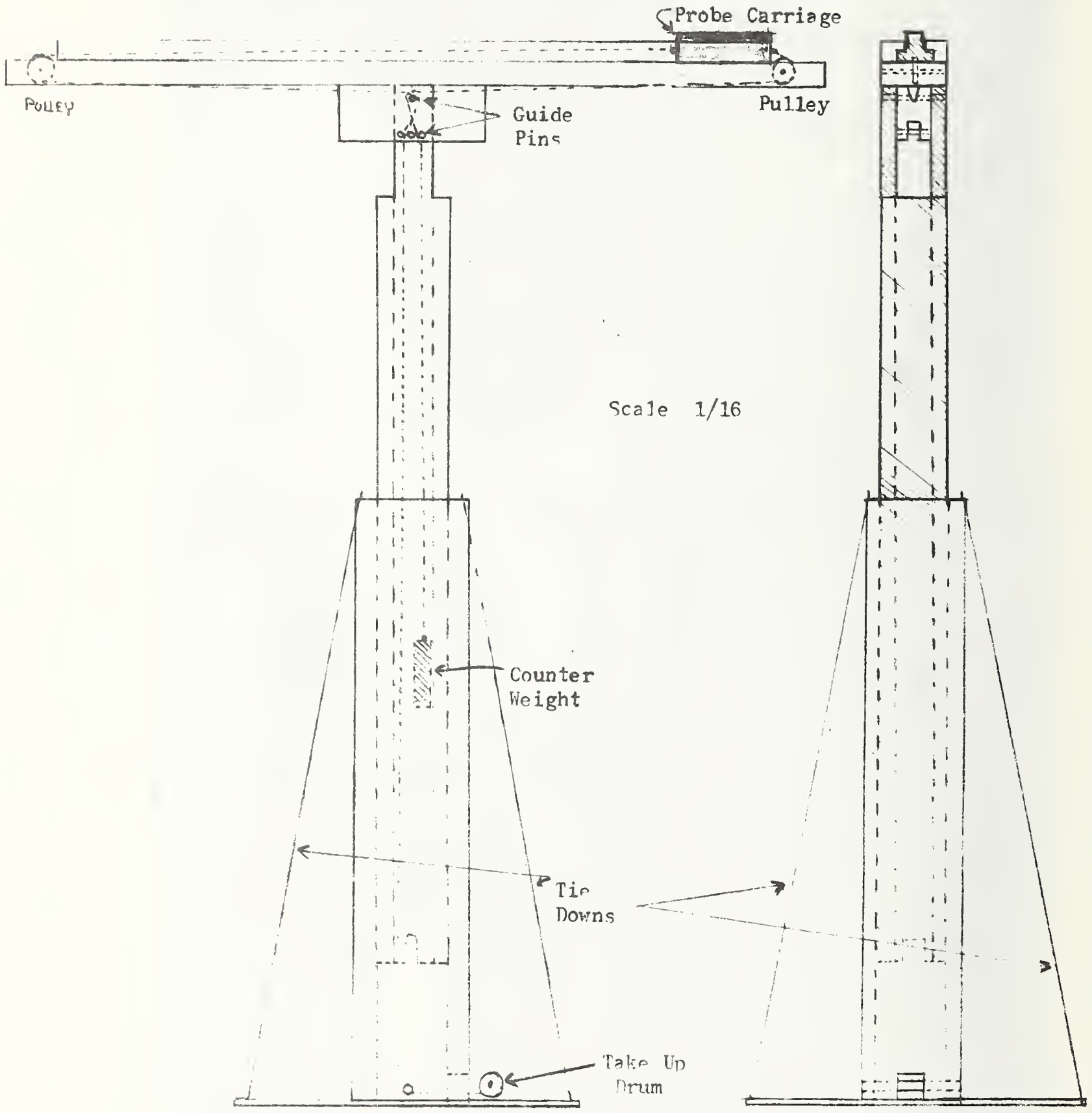

Figurn 13. Field Probe Traversing Mechanicm Detail. 


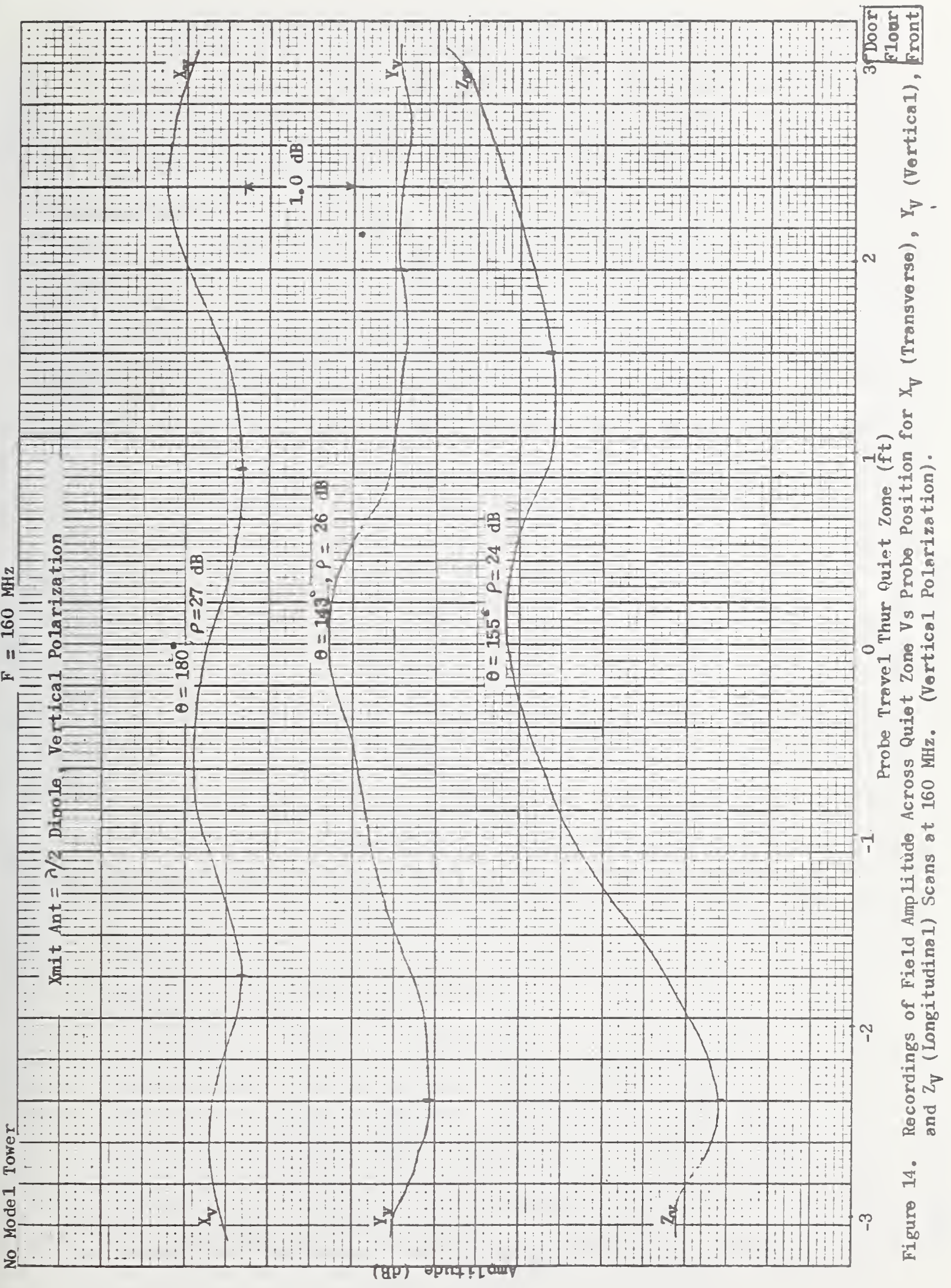




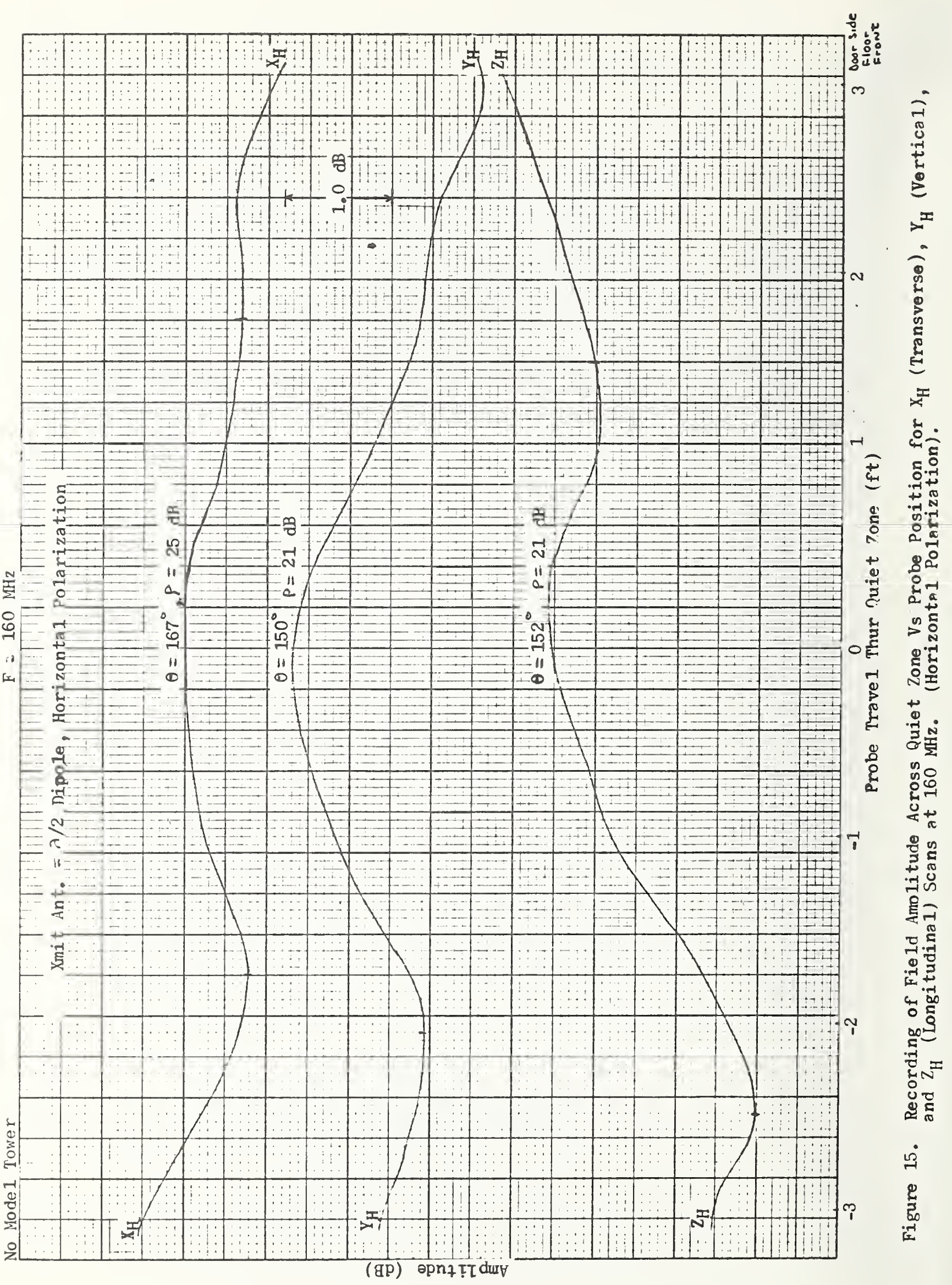




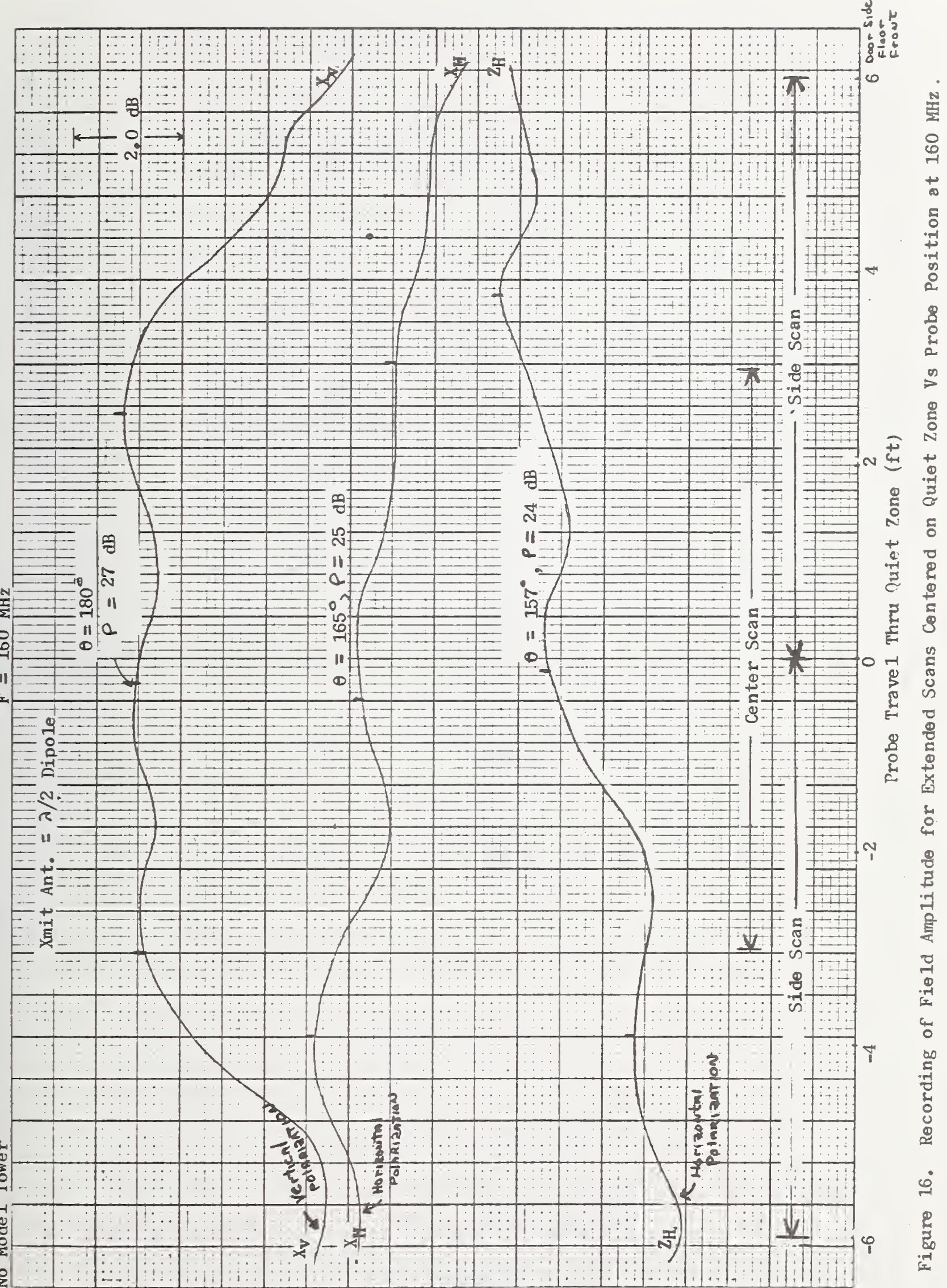




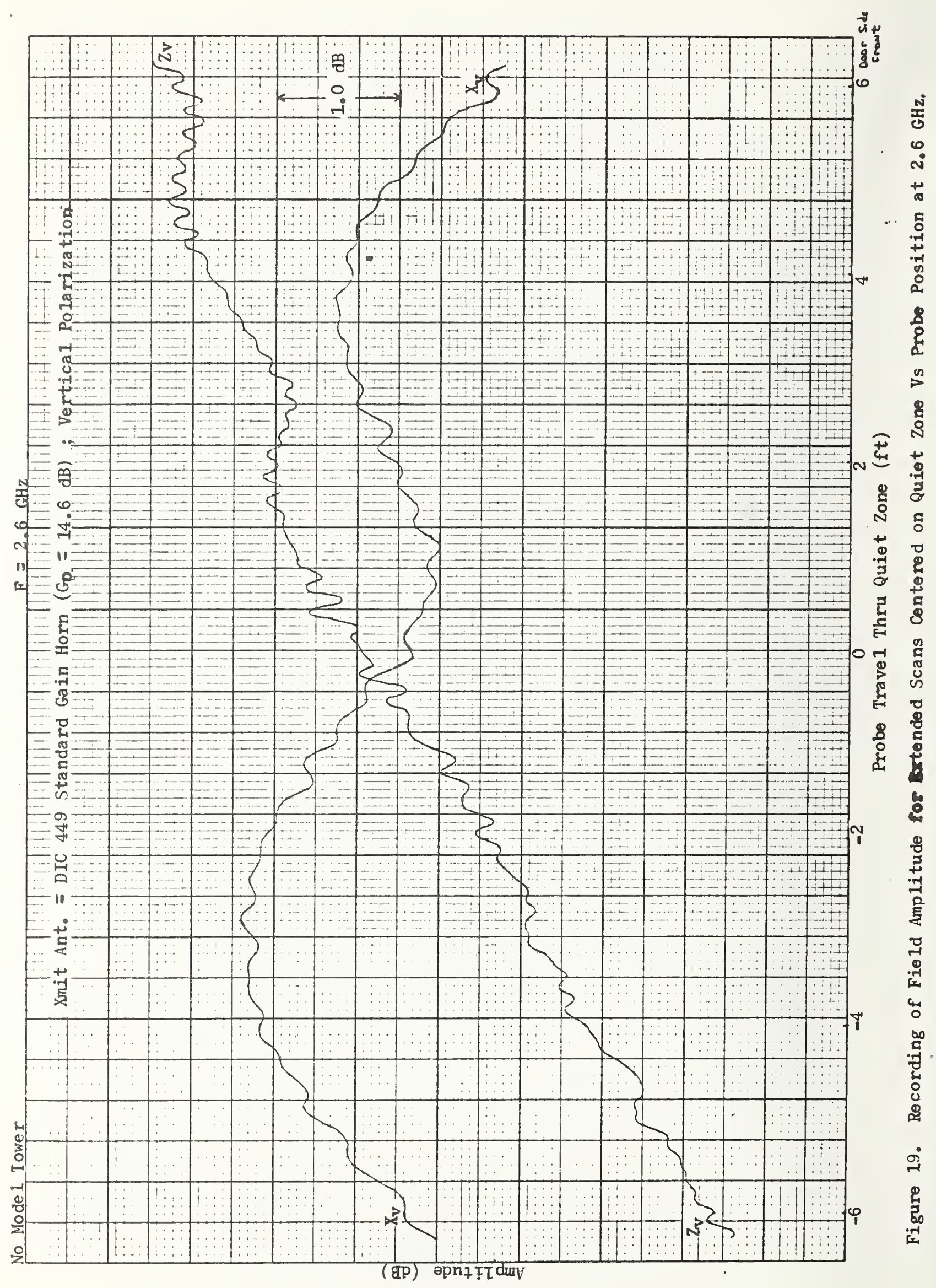




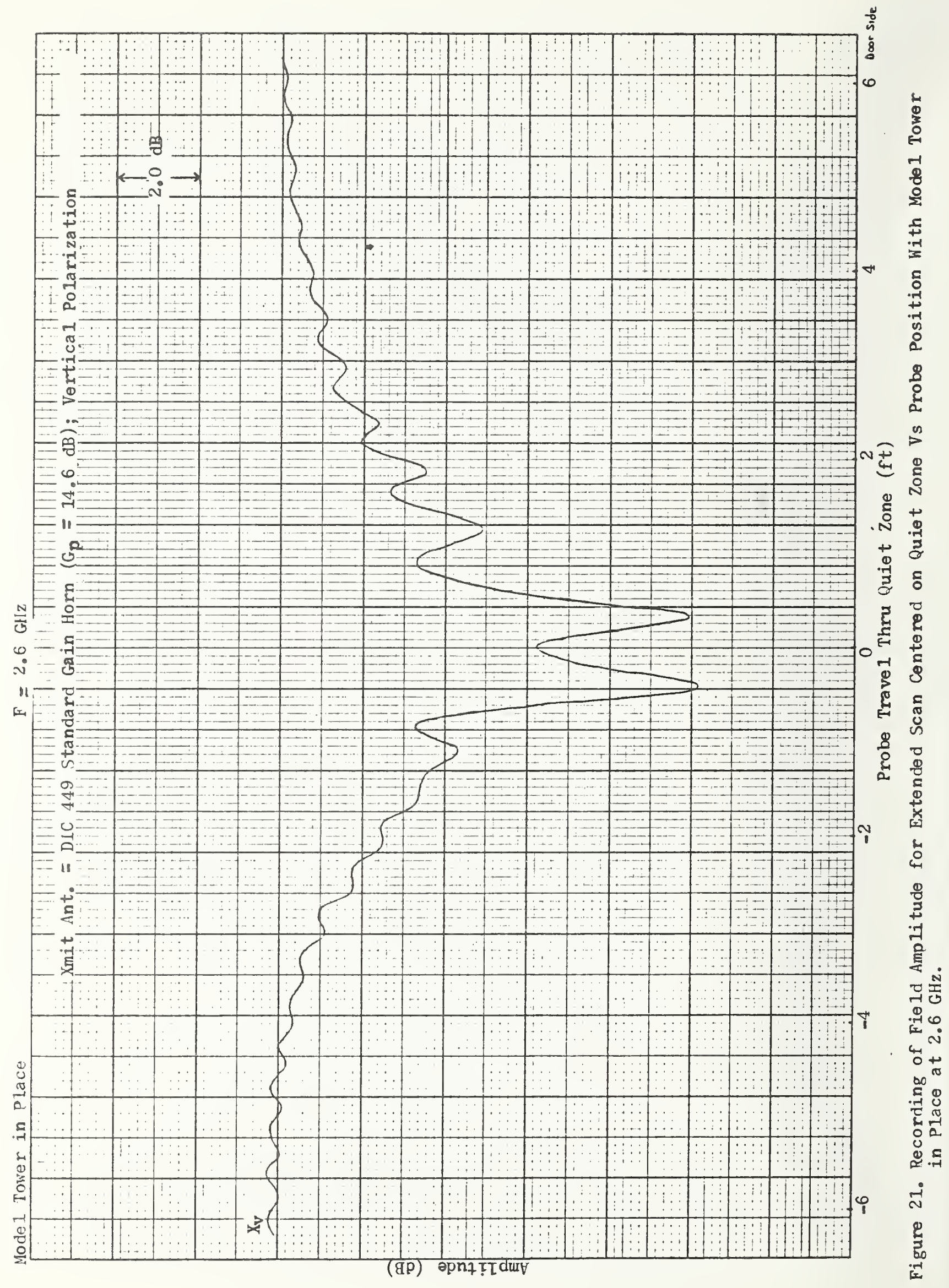




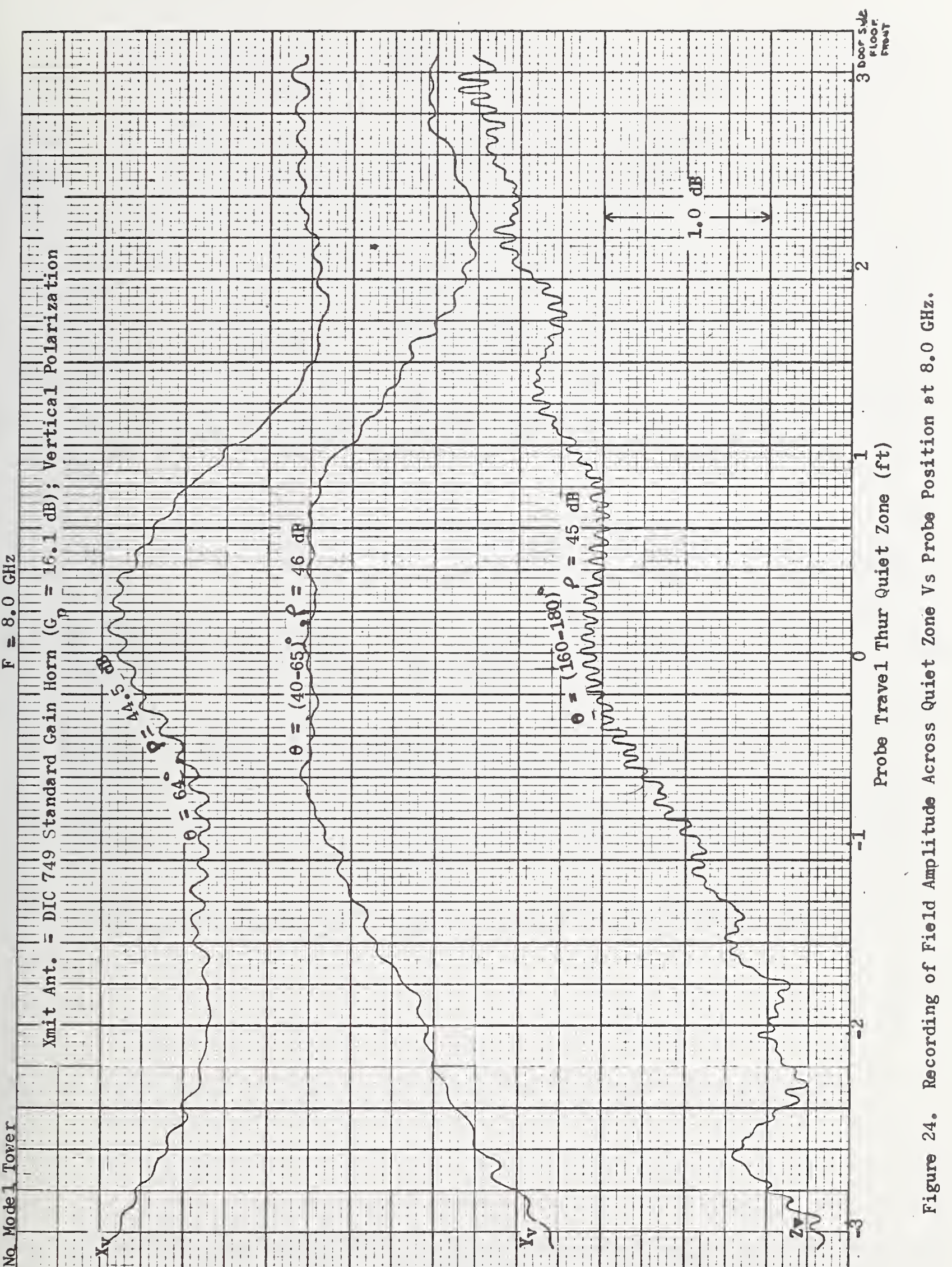




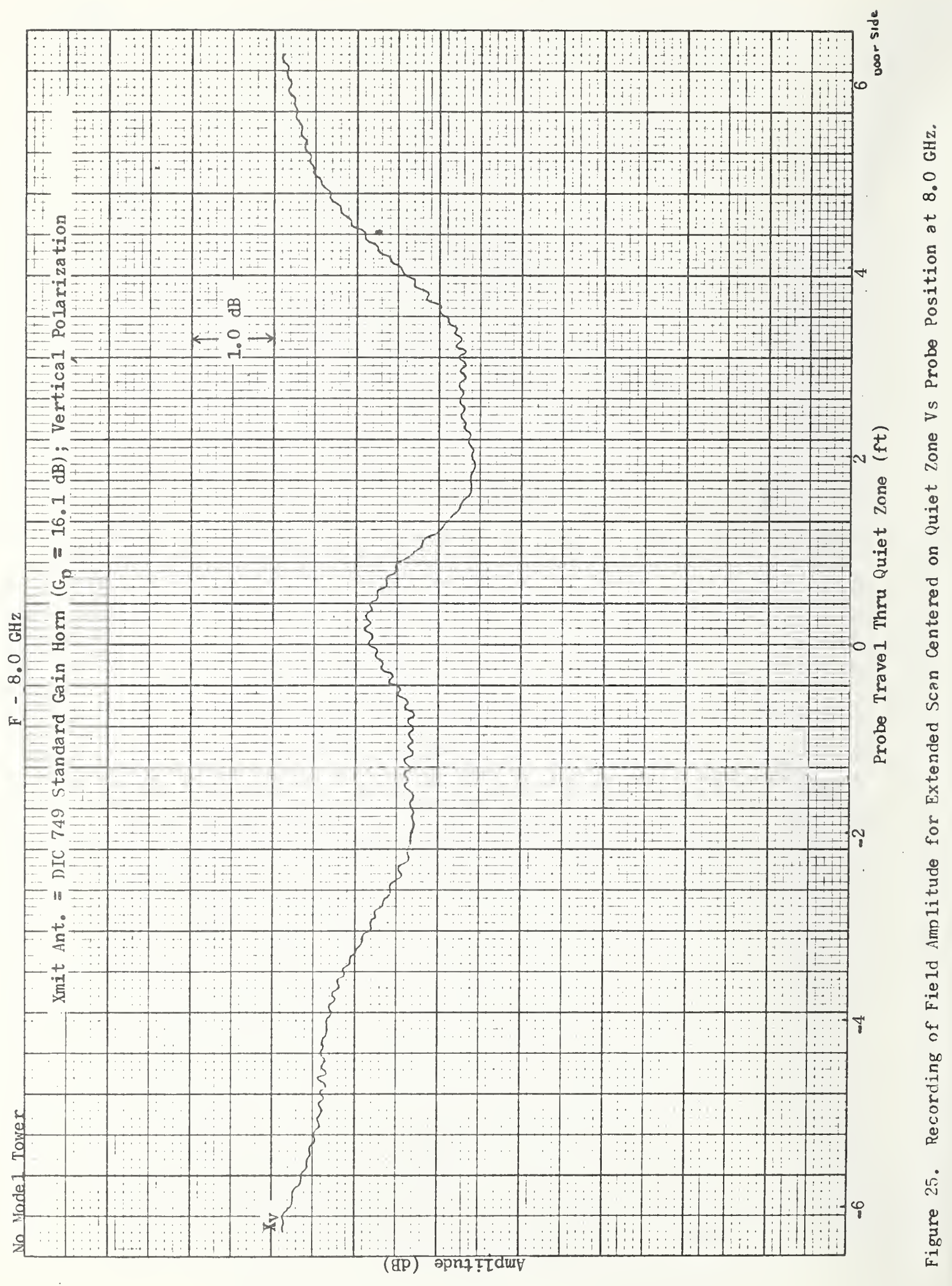




\begin{tabular}{|c|c|c|c|c|}
\hline Freq (MHz) & $\begin{array}{l}\text { Reflectivity } \\
\text { VSWR (dB) }\end{array}$ & $\begin{array}{l}\text { Quiet Zone Fie1 } \\
\mathrm{X} \text { (transverse) } \\
\end{array}$ & $\begin{array}{l}\text { 1d Amplitude V } \\
\mathrm{Y} \text { (vertic 1) }\end{array}$ & $\begin{array}{l}\text { ristion (dB) } \\
2 \text { (1ongitudina1) }\end{array}$ \\
\hline 160 & $24-27$ & 0.7 & 0.9 & 2.3 \\
\hline 2600 & $36-38.5$ & 1.3 & 0.7 & 2.2 \\
\hline 4000 & $41-46$ & 2.4 & 2.3 & 1.5 \\
\hline 8000 & \# $44.5-46$ & 1.3 & 1.6 & 2.0 \\
\hline
\end{tabular}

Figure 26. Sumary of Chamber Quiet Zone Reflectivity and Amplitude Distribution. 

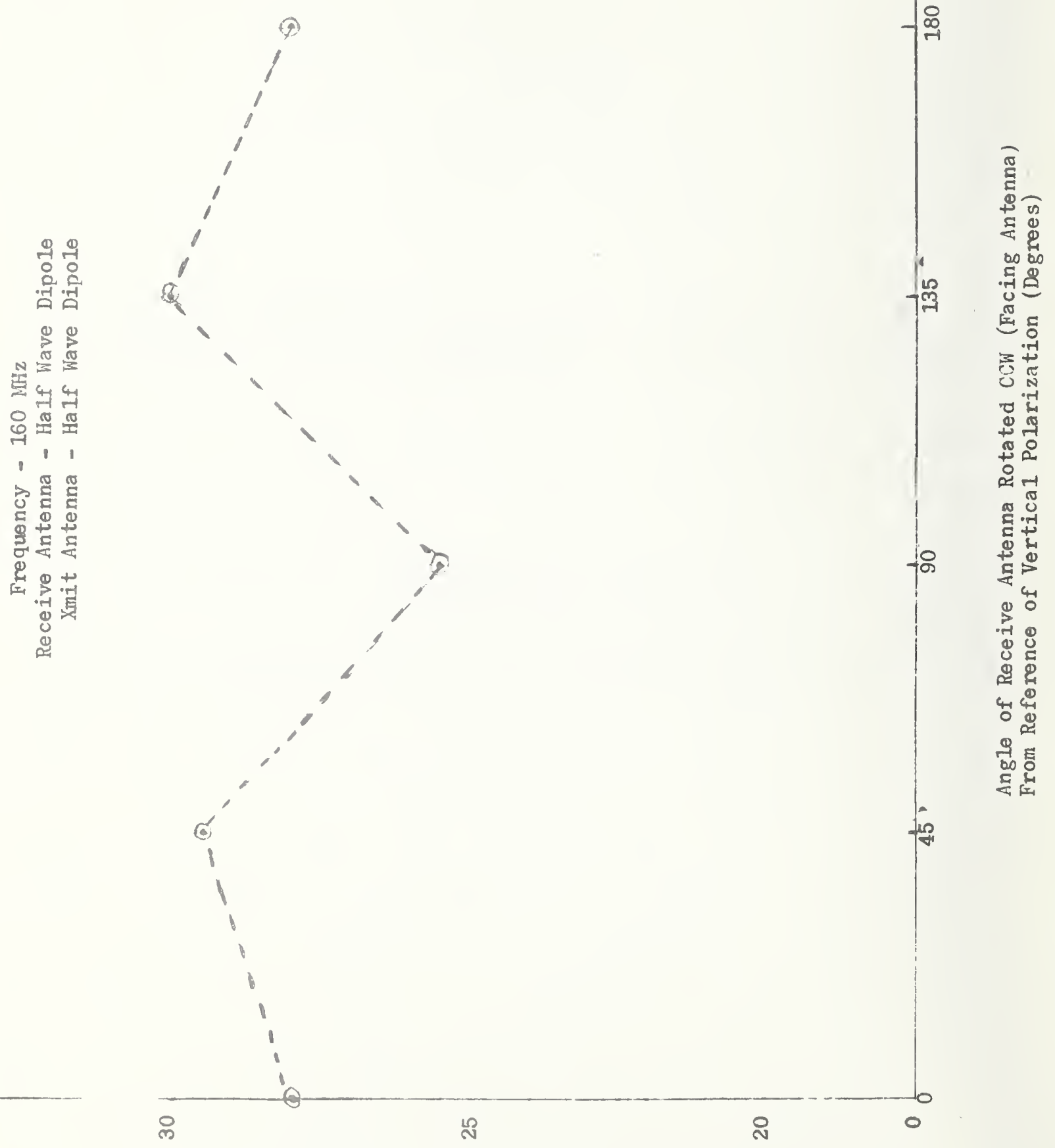

(gp) otqey Ietxy - pozturtod ssoso 
䙵

00

11

5e्e

동홍

. . . .

의 오

퐇판문

엉

N

is

왕ㅇ

F

变品品

网口

\&:

菖莫

$\$$

.

$\stackrel{0}{2}$

$Q$

(1)

c)

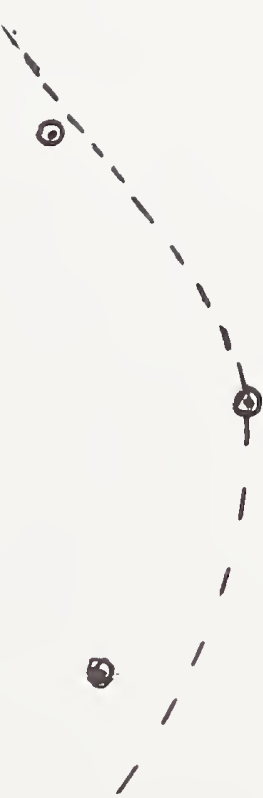

造

ह

5

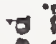

(I)

50

กิศ

苞

零:

告 8

.

के है

诘密

量䂞

急

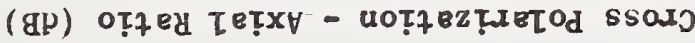



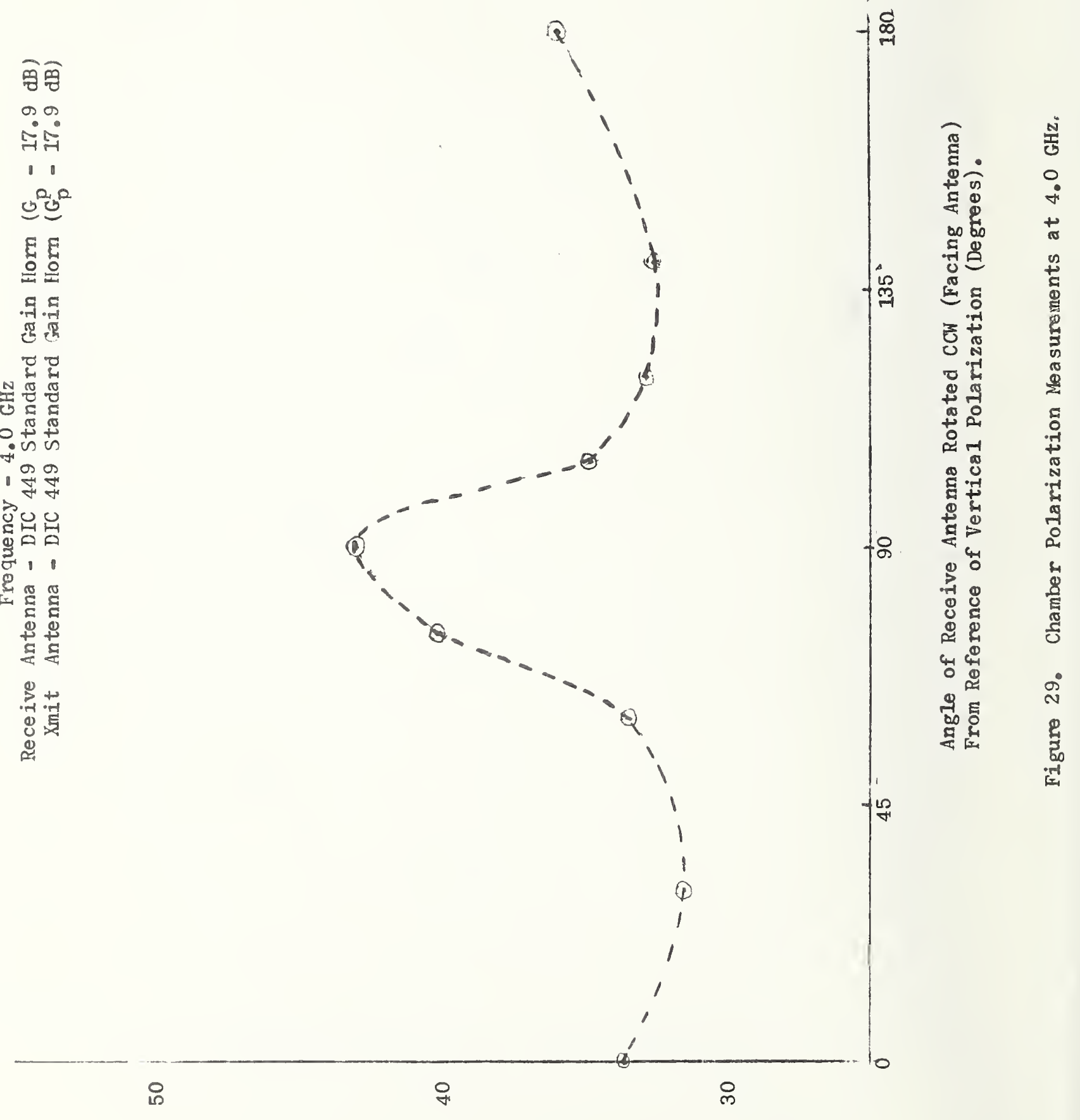

(ap) oțłed I8țxy - pazțxeIod ssars 


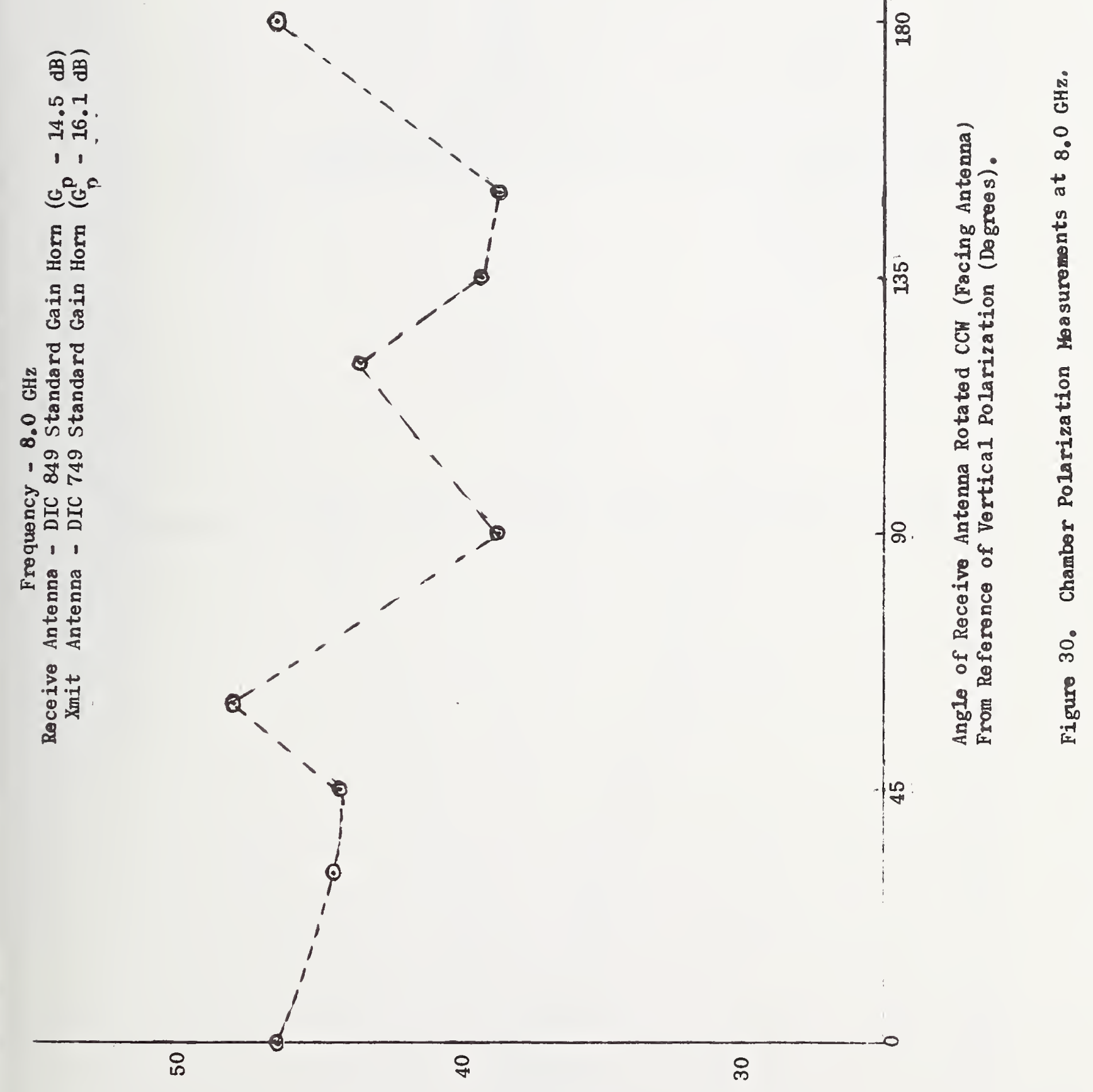




\begin{tabular}{ll} 
Freq (MHz) & $\begin{array}{c}\text { Cross Polarized Antenna } \\
\text { Axial Ratio Variation (dB) }\end{array}$ \\
\hline 160 & $25.5-30$ \\
2600 & $30-43$ \\
4000 & $31.6-43$ \\
8000 & $38.6-48$
\end{tabular}

Figure 31. Sumary of Chamber Symmetery/Polarization Measurements. 


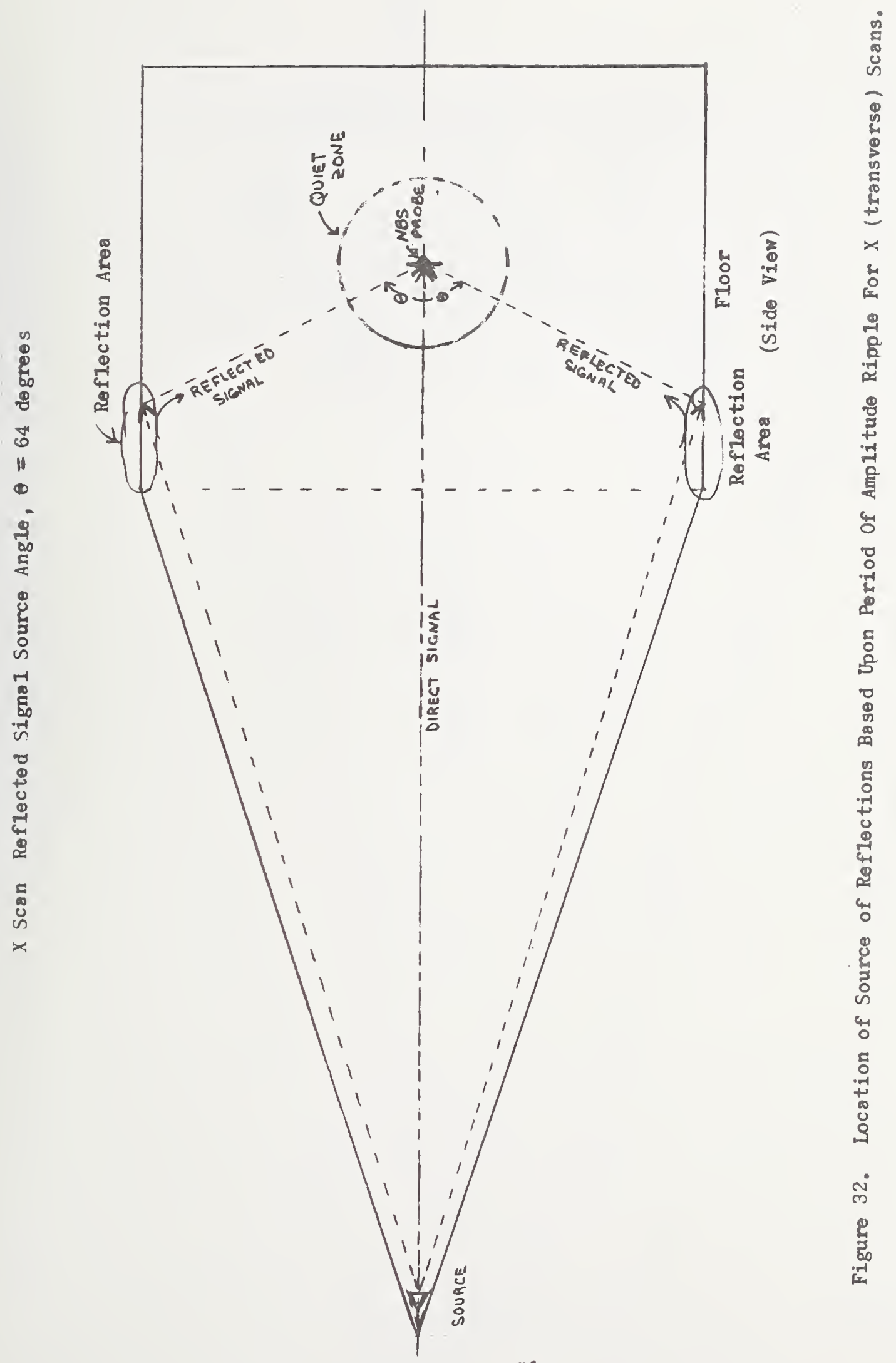




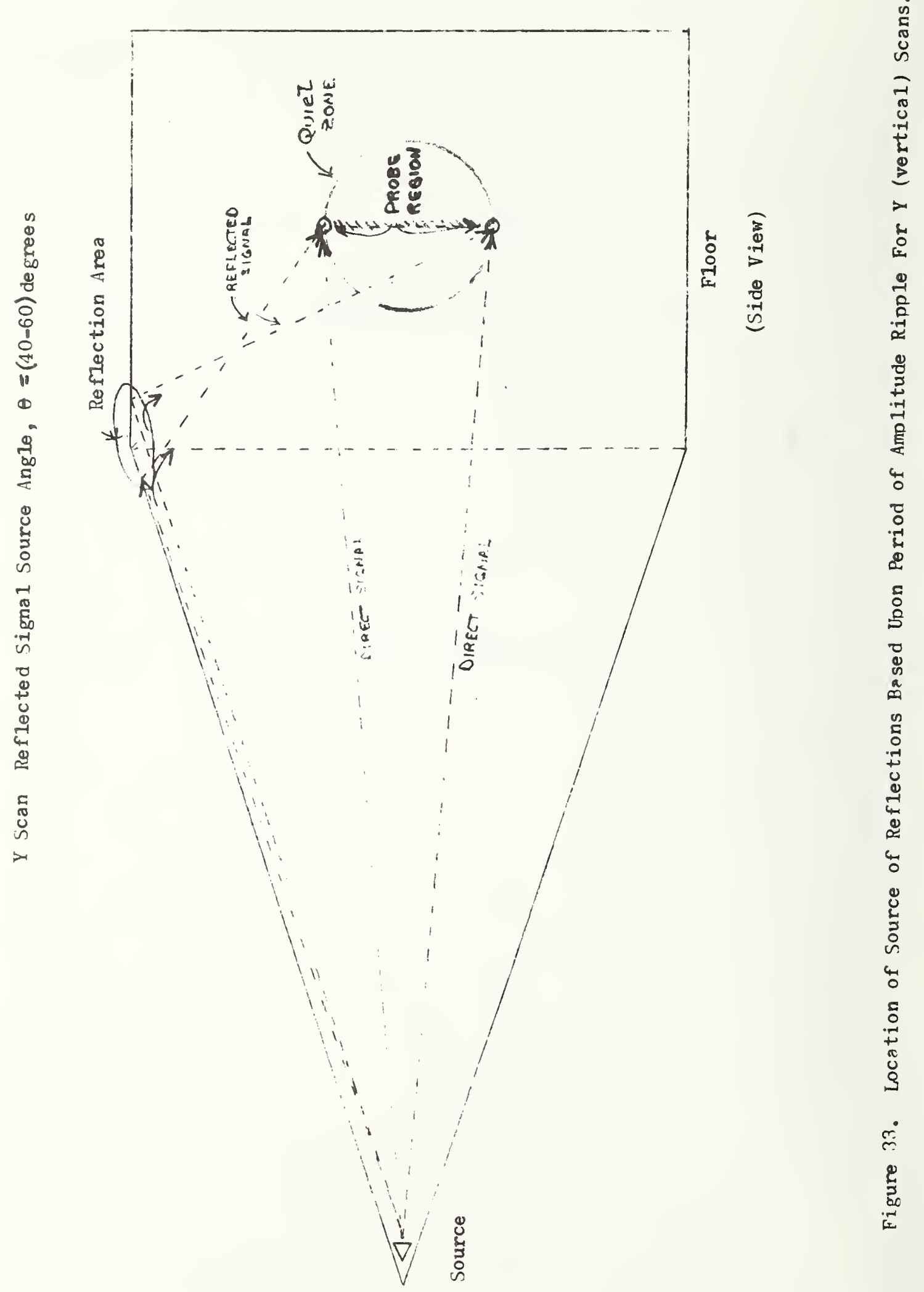




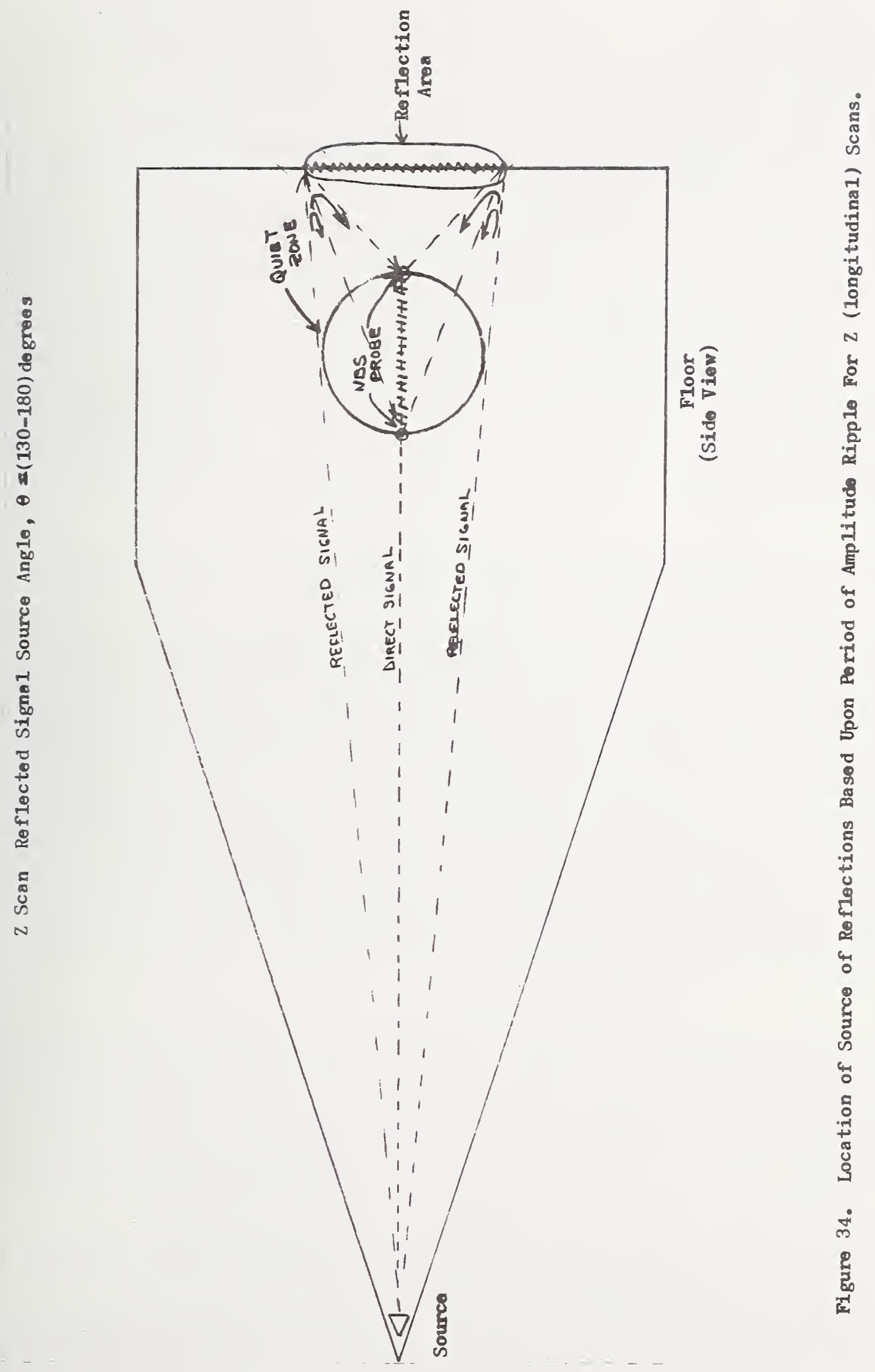


NBS.114A (REV.7-73)

\begin{tabular}{|c|c|c|c|}
\hline $\begin{array}{l}\text { U.S. DEPT. OF COMM. } \\
\text { BIBLIOGRAPHIC DATA } \\
\text { SHEET }\end{array}$ & $\begin{array}{l}\text { 1. PUBLICATION OR REPORT NO. } \\
\text { NBSIR } 74-352\end{array}$ & $\begin{array}{l}\text { 2. Gov't Accession } \\
\text { No. }\end{array}$ & 3. Recipient's Accession No. \\
\hline \multirow{2}{*}{\multicolumn{3}{|c|}{$\begin{array}{l}\text { 4. TITLE AND SUBTITLE } \\
\text { Experimental Evaluation of the U.S. Army, Warrenton } \\
\text { Training Center Anechoic Chamber }\end{array}$}} & $\begin{array}{l}\text { 5. Publication Date } \\
\text { November } 1973\end{array}$ \\
\hline & & & 6. Perfotming Organization Code \\
\hline $\begin{array}{l}\text { 7. AUTHOR(S) } \\
\text { M.L. Crawford }\end{array}$ & & & 8. Performing Organ. Report No. \\
\hline \multirow{3}{*}{\multicolumn{3}{|c|}{$\begin{array}{l}\text { 9. PERFORMING ORGANIZATION NAME AND ADDRESS } \\
\text { NATIONAL BUREAU OF STANDARDS, Boulder Labs } \\
\text { DEPARTMENT OF COMMERCE } \\
\text { Boulder, Colorado } 80302\end{array}$}} & $\begin{array}{l}\text { 10. Project/Task/Work Unit No. } \\
2727484\end{array}$ \\
\hline & & & 11. Contract/Grant No. \\
\hline & & & WTC - 538- 74 \\
\hline \multirow{2}{*}{\multicolumn{3}{|c|}{$\begin{array}{l}\text { 12. Sponsoring Organization Name and Complete Address (Street, City, State, ZIP) } \\
\text { U.S. Army } \\
\text { Warrenton Training Center } \\
\text { Virginia }\end{array}$}} & $\begin{array}{l}\text { 13. Type of Report \& Period } \\
\text { Covered Oct. }- \text { Dec., } 73 \\
\text { NBS Interagency R eport }\end{array}$ \\
\hline & & & 14. Sponsoring Agency Code \\
\hline
\end{tabular}

15. SUPPLEMEN TARY NOTES

16. ABSTRACT (A 200-word or less factual summary of most significant information. If document includes a significant bibliography or literature survey, mention it here.)

This report describes the experimental performance evaluation of a 50 foot tapered anechoic chamber located at U.S. Army, Warrenton T raining Center. Measurements of chamber reflectivity and polarization properties were made at four frequencies, $160 \mathrm{MHz}, 2.4 \mathrm{GHz}, 4.0 \mathrm{GHz}$, and $8.0 \mathrm{GHz}$. The measurement system developed by NBS for measuring chamber reflectivity utilizes a new NBS designed isotropic probe mounted on a polyfoam track and support structure for probing the chamber's quiet zone in all three orthogonal planes. The probe is omni-directional within $1 \mathrm{~dB}$ and has sufficient sensitivity to permit evaluation of reflectivity levels as low as $-59 \mathrm{~dB}$. Complete scattering information is obtained without receive antenna pattern correction with only 3 orthogonal scans per frequency required. The report presents a brief treatment of the theory involved for evaluating the chamber, a description of the measurement system and technique used, the measurement results, and conclusions and recommendations including location of sources of reflection within the chamber.

17. KEY WORDS (six to twelve entries; alphabetical order; capitalize only the first letter of the first key word unless a propet name; separated by semicolons)

Anechoic chamber evaluation; omni-directional probe; polarization; reflectivity; three-dimensional scanning.

18. AVAILABILITY Unlimited

X For Official Distribution. Do Not Release to NTIS

Order From Sup. of Doc., U.S. Government Printing Office Washington, D.C. 20402, SD Cat. No. C13

Order From National Technical Information Service (NTIS) Springfield, Virginia 22151

\begin{tabular}{|l|l|}
\hline $\begin{array}{l}\text { 19. SECURITY CLASS } \\
\text { (THIS REPORT) }\end{array}$ & 21. NO. OF PAGES \\
UNCLASSIFIED & 22. Ptice \\
\hline $\begin{array}{l}\text { 20. SECURITY CLASS } \\
\text { (THIS PAGE) } \\
\text { UNCLASSIFIED }\end{array}$ & USCOMM-DC 29042.P74 \\
\hline
\end{tabular}

ISCOMM . ERI. 